Est Ag 39 (2004)323-37.

\title{
Identidad e iniciación cristiana (III)
}

\section{LA INICIACIÓN COMO PROCESO PARA ADQUIRIR LA IDEN- TIDAD CRISTIANA HOY}

El catecumenado clásico, como hemos indicado, fue decayendo progresivamente a medida que el cristianismo se fue convirtiendo en la religión oficial del Imperio. Podemos afirmar que, a partir del siglo VI, la degradación de la estructura iniciática clásica, que había empezado a producirse a partir del siglo IV1, llegó a su plenitud con el olvido de la estructura iniciática primitiva y con la desmembración de los sacramentos de iniciación en occidente ${ }^{2}$. Esta situación se mantuvo, salvo excepciones, hasta el siglo que ahora termina ${ }^{3}$. Los estudios históricos, patrísticos y litúrgicos, así como la experiencia en los países de misión, cristalizaron en la reforma del Vaticano II $^{4}$ y en el Ritual de

1. Cf. X. BASURKo, Hacia una pastoral del bautismo, en Teología y Catequesis 18 (1986) 252.

2. Cf. N. MITCHELL, Christian Initiation: Decline and Dismemberment, en Worship 48 (1974) 458-479; A. KAVANAGH, Initiation: Baptism and Confirmation, 271.

3. Cf. M. DUJARIER, Breve historia del catecumenado, 133-142. "Conviene recordar que la iniciación cristiana históricamente se ha desarrollado en distintos niveles de exigencia. Un proceso iniciático cristiano 'sensu stricto' sólo se conoció en la edad de oro catecumenal, entre los siglos II y VI. La invasión de los bárbaros y su llegada masiva a la fe modificó profundamente el instrumento de socialización cristiana, rebajando las exigencias a niveles medios y mínimos. [...] Hasta el siglo XIX no se reconstruye el catecumenado, y solo para los nuevos cristianos en países de misión." (M. MATOS, Intento de descripción de los itinerarios iniciáticos más comunes en la actual práctica eclesial española, en Teología y Catequesis 28 (1988) 623). Preferimos la opinión de otros autores que consideran que el catecumenado funcionó con seriedad y calidad durante un periodo mucho más breve cf. G. GROPPO, Catecumenado antiguo, 146; M. DUJARIER, Breve historia del catecumenado, 121124; 132; X. BASURKO, Hacia una pastoral del bautismo, 522; X. BASURKO, La eucaristía en la iniciación cristiana, en Teología y Catequesis (1991) 67; D. BOROBIO, Confirmación e iniciación cristiana, 42-43; D. BOROBIO, Catecumenado, 133-139; J. LÓPEZ SÁEZ, Catecumenado e inspiración catecumenal, 286; M. del CAMPO GUILARTE, Iniciación cristiana, La, en V. $\mathrm{M}^{\mathrm{a}}$ Pedrosa et al., Nuevo diccionario de catequética I, San Pablo, Madrid 1990, 1243.

4.Cf. M. DUJARIER, Breve historia del catecumenado, 142-151; E. ALBERICH, Catecumenado moderno, en J. Gevaert (dir.), Diccionario de catequética, CCS, Madrid 1987, 149150; J. LÓPEZ SÁEZ, Catecumenado e inspiración catecumenal, 286-287; M. del CAMPO GUILARTE, Iniciación cristiana, $L a, 1243$. Para profundizar en el RICA a la luz de los testimo- 
Iniciación Cristiana de Adultos promulgado el día de la Epifanía del año 1972. Este Ritual, quizá el mejor del post-concilio, es más importante por lo que sugiere que por la materialidad de sus oraciones y símbolos concretos. A partir de él se pueden valorar más ajustadamente, corregir y potenciar otros aspectos que no se contemplan tanto en los rituales como en la pastoral del bautismo y la confirmación. Con todo, consideramos que lo más importante del RICA no es lo que expresamente dice cuanto el espíritu que deja traslucir respecto al origen, crecimiento y maduración en la fe.

\section{III.1.- La iniciación cristiana es temporal, gradual y comunitaria (cf. RICA, 4).}

La persona es un ser histórico. Por esta razón, el crecimiento y la maduración de la fe y conversión inicial también necesita de una suficiente duración temporal. No se puede, a priori, determinar el tiempo necesario para la plena iniciación pues, siendo un camino espiritual, depende de múltiples factores: la gracia de Dios, la libre cooperación del candidato, la acción de la comunidad eclesial y las circunstancias de tiempo y lugar (cf. RICA, 5) ${ }^{5}$. De hecho esta constatación ya la hacía Hipólito de Roma como ya vimos en su momento 6 .

"La iniciación para la mayoría de edad social en las modernas sociedades civilizadas lleva décadas, no semanas; la 'consagración' de un moderno jefe de Estado lleva meses, cuando no años, y la ceremonia culminante dura varios días, no unos minutos. Los cristianos empobrecen sus sacramentos cuando los reducen a unos argumentos momentáneos, con lo que no se asegura la 'noble sencillez', sino únicamente una falta de vigor, de continuidad y de ritmo. Porque un rito, litúrgico o de cualquier otra clase, es mucho más que un código de comunicación. Es además lo que Víctor Turner llama '... una sincronización de muchos géneros representativos... ordenados frecuentemente por una estructura dinámica que confiere energía y color emotivo a los códigos de comunicación interdependientes que expresan en una diversidad y multiplicidad de formas el significado del tema central'. El rito exige la participación no sólo de la mente, sino también de

nios patrísticos cf. C. ELORRIAGA, Bautismo y catecumenado en la tradición patrística y litúrgica (Una selección de textos), Grafite, Baracaldo 1998.

5. Para una sugerente exposición de cómo se articula la iniciativa de Dios, la respuesta del candidato y la acción de la comunidad cf. A. KAVANAGH, Initiation: Baptism and Confirmation, 265-268.

6. "Pero, si alguno fuera celoso y aplicado en el cumplimiento de sus obligaciones, no se juzgará el tiempo, sino solamente su conducta" (Trad. Apost. 17). 
los sentidos y las emociones, y todo ello modulado en expresiones cinestéticas (danza y gesto) y sonoras"7.

Al ser el tiempo un factor determinante, el camino de iniciación cristiana se articula por grados que, a modo de escalones, van marcando el avance en las etapas de maduración. El modelo de iniciación cristiana que ofrece el RICA se estructura en torno a 'tiempos' y 'grados' que el candidato ha de ir franqueando para crecer y madurar en la fe. Cada grado introduce en un tiempo, más o menos prolongado, de discernimiento y madurez que le vaya preparando para el siguiente grado ${ }^{8}$. De esta manera, los tiempos y los grados se entrecruzan para formar la estructura general de la iniciación cristiana de adultos propuesta en el Ritual.

Ya hemos apuntado que la iniciación cristiana en la época patrística no fue uniforme en las diferentes iglesias locales ${ }^{9}$. La estructura profunda de la iniciación cristiana que propone el RICA es deudora de la praxis de iniciación en los primeros siglos de la Iglesia y mantiene elementos que responden al esquema de toda iniciación. Uno de estos elementos es la secuencia ritual de tiempos y ritos de separación, margen y agregación. El RICA se estructura como una sucesión de cuatro tiempos o etapas (precatecumenado, catecumenado, tiempo de la purificación y de la iluminación, y mystagogia) y tres grados (entrada en el catecumenado, elección o inscripción del nombre y la celebración de los sacramentos de iniciación cristiana) ${ }^{10}$.

\section{a) Temporal...}

Los tiempos o etapas son espacios pastorales, más o menos prolongados en función de la fe de los aspirantes, durante los cuales los iniciandos buscan el crecimiento de su fe respondiendo a las propuestas evangelizadoras de la comunidad que les está iniciando. Los tiempos o etapas del RICA son cuatro y se inspiran en el catecumenado clásico: 1)Precatecumenado, 2) Catecumenado11, 3) Purificación e iluminación y 4) Mystagogia12. Estas cuatro etapas

7. A. KaVANAGH, Los acontecimientos del ciclo vital, 174. Está citando a V.Turner, Ritual, tribal and catholic, en Worship 50 (1976) 505.

8. Gradual en griego es_v $v \alpha \theta \mu_{-} v$ (anabazmon) cf. SAN AGUSTín, In. Ps. 119, 1.

9. Cf. SAN AMBrosio, De Sacr. 3,1,4-7. Los ejemplos referentes a las peculiaridades de cada Iglesia en lo que concierne a la iniciación se podrían multiplicar indefinidamente hasta incluir diferencias de los credos.

10. Cf. L. DELLA TORRE, Iniciación cristiana de los adultos (Ritual de la), en J. Gevaert (dir.), Diccionario de catequética, CCS, Madrid 1987, 468.

11. Cf. M. DUJARIER, Iniciación cristiana de los adultos, 67-94. 
son, por parte de la comunidad, de educación y, por parte del iniciando, de maduración ${ }^{13}$.

\begin{tabular}{|c|c|c|}
\hline Etapas & Objetivo & Acento \\
\hline precatecumenado & $\begin{array}{l}\text { primera evangelización } \\
\text { (despertar de la fe) }\end{array}$ & $\begin{array}{l}\text { conversión que se intenta suscitar } \\
\text { en el candidato }\end{array}$ \\
\hline catecumenado & $\begin{array}{l}\text { catequesis integral } \\
\text { (educación de la fe) }\end{array}$ & $\begin{array}{l}\text { esfuerzo por adquirir la formación } \\
\text { vital de la fe y vida cristiana }\end{array}$ \\
\hline $\begin{array}{l}\text { purificación e } \\
\text { luminación }\end{array}$ & $\begin{array}{l}\text { preparación espiritual más intensa } \\
\text { (consagración de la fe) }\end{array}$ & formación espiritual \\
\hline mistagogia & $\begin{array}{l}\text { nueva experiencia de los sacramen- } \\
\text { tos y la comunidad } \\
\text { (vida de fe) }\end{array}$ & $\begin{array}{l}\text { experiencia espiritual ordenada } \\
\text { a gustar los frutos del Espíritu en } \\
\text { una convivencia más intensa con } \\
\text { la comunidad de los fieles }\end{array}$ \\
\hline
\end{tabular}

Esta sucesión de tiempos puede ser interpretada de la siguiente manera: el tiempo de separación comprendería el tiempo del pre-catecumenado; el catecumenado junto con la cuaresma (tiempo de purificación e iluminación) se constituirían como el tiempo de margen; la celebración de los sacramentos de iniciación y la mistagogia podrían entenderse como los ritos y el tiempo de agregación. De esta manera, nos quedaría un cuadro como el que sigue:

\begin{tabular}{|l|l|}
\hline $\begin{array}{l}\text { Secuencia } \\
\text { ritual } \\
\text { de paso }\end{array}$ & Secuencia de la iniciación cristiana en el RICA \\
\hline separación & desde el comienzo del precatecumenado hasta la entrada en el catecumenado \\
\hline Margen & catecumenado y tiempo de purificación e iluminación \\
\hline agregación & $\begin{array}{l}\text { celebración del los sacramentos de iniciación en la vigilia pascual y el tiempo } \\
\text { de la mistagogia }\end{array}$ \\
\hline
\end{tabular}

12. Cf. M. DUJARIER, Iniciación cristiana de los adultos, 185-203.

13. Para el cuadro adjunto cf. R. GONZÁlEZ, La mistagogía en el Ritual de la Iniciación Cristiana de Adultos, en Phase (1992) 383-384; M. DUJARIER, Iniciación cristiana de los adultos, 22-27; 30-33. 
Quizá esta forma de entender el RICA, en correspondencia con la secuencia ritual de los ritos de paso y, por ende, de la iniciación, pueda ser a primera vista satisfactoria. Pero las cosas se complican cuando visto de cerca, el RICA propone una serie de ritos compuestos de otros más sencillos con significados diversos. Un esquematismo tajante no hace justicia, pues el Ritual tiene tres grados -en los que cada uno de ellos encontramos, al mismo tiempo, ritos de separación, margen y agregación-y las cuatro etapas, a las que nos estamos refiriendo, que se constituyen como tiempos de margen suficientemente desarrollados como para desdoblarse y constituir etapas relativamente 'autónomas', aunque articuladas y ordenadas mutuamente entre sí.

"Si el esquema completo de los ritos de paso incluye [...], en teoría, ritos preliminares (separación), liminares, (margen) y postliminares (agregación), en la práctica dista mucho de haber una equivalencia de los tres grupos, bien por su importancia, bien por su grado de elaboración.

Por lo demás, en algunos casos el esquema se desdobla: tal es el caso cuando el margen se halla lo bastante desarrollado como para constituir una etapa autónoma"14.

Debido a que en el RICA los cuatro tiempos tienen un desarrollo suficientemente importante, no podemos afirmar rotundamente que, por ejemplo, el rito de entrada en el catecumenado sea simplemente un rito de separación, pues en él encontramos elementos que nos remiten también a una agregación (v.gr. la imposición de un nombre nuevo, arrojar sal, introducción en el templo) ${ }^{15}$.

\section{b) Gradual...}

Los grados en el RICA son los pasos de un tiempo a otro. A modo de umbrales que se van atravesando en el crecimiento de la fe inicial hasta la fe madura, cada uno de los tres grados del RICA condensa el tiempo anterior y abre hacia el siguiente. De esta manera, los grados van marcando los momentos nucleares de la iniciación dando acceso a etapas cada véz más profundas en la maduración de la fe. Cada uno de los grados celebra la conversión previa en una mayor profundidad y proyecta hacia un nuevo tiempo destinado a un crecimiento mayor de la fe en el camino de la iniciación.

14. VAN GENNEP, A.; Los ritos de paso, 20-21.

15. "Si existieran algunas costumbres locales aptas para significar la entrada en la comunidad [...] se pueden añadir antes o después del ingreso en el templo." (RICA 89) 
Los grados que el RICA contempla son los siguientes: 1) Entrada en el catecumenado ${ }^{16}$;2) Elección o inscripción del nombre ${ }^{17}$;3) Celebración de los sacramentos de la iniciación. Estos grados son celebrados por los tres ritos más significativos de todo el ritual. Son, lo que podríamos denominar en terminología de Van Gennep, tres ritos de separación o agregación dependiendo del punto de vista que adoptemos. En primer lugar, los tres grados del RICA pueden ser considerados como ritos separación en la medida que, los que se someten a ellos, dejan atrás un estado previo de fe y clausuran el tiempo de margen que habían vivido hasta ese momento. En segundo lugar, estos tres ritos pueden ser considerados como de agregación. en la medida que introducen en un nuevo tiempo o etapa liminar en la que tendrán que seguir madurando la vida de fe en sus diferentes aspectos.

En el siguiente cuadro intentamos resumir las dos posibles interpretaciones de cada uno de los grados del RICA según se contemplen como ritos de separación o de agregación.

\begin{tabular}{|lll|}
\hline \multicolumn{1}{|c}{ Grado } & \multicolumn{1}{c|}{ Rito de separación } & \multicolumn{1}{c|}{ Rito de agresión } \\
\hline $\begin{array}{l}\text { Entrada en el cate- } \\
\text { cumenado }\end{array}$ & $\begin{array}{l}\text { separa del tiempo del precatecu- } \\
\text { menado }\end{array}$ & $\begin{array}{l}\text { da acceso al tiempo del } \\
\text { catecumenado }\end{array}$ \\
\hline $\begin{array}{l}\text { elección o inscrip- } \\
\text { ción del nombre }\end{array}$ & $\begin{array}{l}\text { separa del tiempo del catecume- } \\
\text { nado }\end{array}$ & $\begin{array}{l}\text { da acceso al tiempo de } \\
\text { purificación e iluminación }\end{array}$ \\
\hline $\begin{array}{l}\text { sacramentos de ini- } \\
\text { ciación cristiana }\end{array}$ & $\begin{array}{l}\text { separa del tiempo de purifica- } \\
\text { ción e iluminación }\end{array}$ & $\begin{array}{l}\text { da acceso al tiempo de la } \\
\text { mistagogia }\end{array}$ \\
\hline
\end{tabular}

El RICA se estructura como un proceso de iniciación y, como tal, participa de muchas de las características de los rituales de paso. Como proceso, se entiende que el iniciando ha de ir haciendo un "camino espiritual" (RICA 5) en el que "hay 'grados' o etapas, mediante los cuales el catecúmeno ha de avanzar, atravesando puertas, por así decirlo, o subiendo escalones." (RICA

16. Cf. M. DUJARIER, Iniciación cristiana de los adultos, 35-66.

17. Cf. M. DUJARIER, Iniciación cristiana de los adultos, 95-114. A. Nocent parece confundir el 'segundo grado' de la iniciación (elección o inscripción del nombre) con la 'tercera etapa' de la iniciación (tiempo de la purificación e iluminación) cf. A. NOCENT, Iniciación cristiana, 1060;1062. Tampoco se ajusta a los testimonios patrísticos lo que dice respecto al rito de la elección o inscripción del nombre: "La antigua praxis catecumenal ponía este último rito al principio del catecumenado, antes del comienzo de la prueba trienal, y se celebraba el primer domingo de cuaresma" (A. NOCENT, Iniciación cristiana, 1062). 
6). Por esta razón, el Ritual es un medio que está en función de lo verdaderamente importante en cualquier iniciación: el itinerario interior que ha de recorrer el que desea convertirse en cristiano. ${ }^{18}$ Como en todo camino iniciático, los ritos que simbolizan la separación o ruptura del candidato con su vida previa así como los de agregación a su nuevo estatus, son ritos del umbral colocados en momentos que simbólicamente hacen presente lo que realmente ha de ir aconteciendo en la vida del iniciando hasta llegar a ser plenamente un cristiano. La pura ritualidad no garantiza la progresión iniciática. Vaciar estos ritos del significado que tienen aboca a un puro formalismo que nada tiene que ver con iniciación alguna."Este crecimiento [de la iniciación catecumenal] se opera entre dos umbrales, la admisión al catecumenado y la admisión a los sacramentos de la iniciación, que no pueden ser franqueados sino cuando las condiciones necesarias están satisfechas"19.

"[...] el itinerario de la iniciación cristiana comporta dos períodos, cada uno de los cuales conduce al paso de un umbral importante. Ante todo hay un período de evangelización, que conduce a un primer umbral: es la etapa de la entrada en el catecumenado. Con esta ceremonia, la Iglesia reconoce al convertido como cristiano y lo acoge en su seno para formarlo. El segundo período es el de la educación en la fe y en la vida evangélica: es el tiempo del catecumenado, en el transcurso del cual la comunidad hace descubrir al nuevo cristiano la enseñanza da Cristo y le enseña a vivir según el Evangelio. Esta formación conduce a un segundo umbral: la etapa de la llamada decisiva. Con esta ceremonia, la Iglesia llama al catecúmeno, llegado a ser elegido, a recibir los sacramentos de la iniciación que harán de él un fiel" 20 .

De esta manera, temporalidad y gradualidad son dos características de la iniciación cristiana propuesta como paradigmática ya que se trata de un proceso con una secuencia progresiva que va desde la lejanía de la fe hasta su plena aceptación ${ }^{21}$. El objetivo final es, por tanto, abandonar la antigua vida para introducir a la persona en la vida nueva de Cristo por medio de y en su gran sacramento: la Iglesia.

18. Cf. M. DUJARIER, Iniciación cristiana de los adultos, 28.

19. M. DUJARIER, Iniciación cristiana de los adultos, 77.

20. M. DUJARIER, Iniciación cristiana de los adultos, 95 . "Mi experiencia pastoral me dice que a los 16-17 años cuando se confirman los adolescentes están más cerca de la conversión inicial que de la conversión radical." (J. SASTRE, Algunas claves para una pastoral renovada del sacramento de la confirmación, 66).

21. "Tratándose del Ritual que la Iglesia ofrece a los pastores para llevar a una persona adulta del estado de pagano al de cristiano, debe ser modelo de conducción, prepara- 


\section{c) ... y comunitaria}

"Cualquier proceso de iniciación es iniciación en las vidas de otra gente: en sus esperanzas y sueños, en sus visiones e ideales"22. Así, la que la iniciación cristiana sólo puede llevarse a cabo en conexión con la comunidad de los fieles que, renovando su propia conversión, y mediante su ejemplo induce a los catecúmenos a seguir al Espíritu Santo con generosidad (cf. RICA, 4).

Por encima de la concepción individualista de la salvación y de la fe, el RICA acentúa la comunidad en su visibilidad sacramental que pide al postulante gestos de su conversión y le acompaña en su progresiva iniciación al misterio de Cristo. El camino de iniciación cristiana aparece, de esta manera, como una acción eclesial y no, simplemente, como individual ${ }^{23}$. No es suficiente el cumplir con los rituales inciáticos para convertirse en cristiano. Es necesario dejarse transformar realmente por ellos según sus significados y exigencias para llegar a convertirse en parte real de la Iglesia que inicia.

La credibilidad de la Iglesia se está dilucidando constantemente en su capacidad para iniciar a nuevos candidatos en el misterio de Cristo del que ella se proclama sacramento. A este respecto, surge una nueva dificultad pues, para que pueda llevarse a cabo la iniciación cristiana, es necesario por parte del candidato, al menos de manera incipiente, una fe en la Iglesia, una confianza en que ella sea capaz de conducirle al encuentro con Cristo, un fiarse de la comunidad local concreta para que ella le vaya orientando progresivamente a la iniciación plena ${ }^{24}$. Para que esta confianza inicial pueda surgir, la

ción y celebración de la fe antes, en y después de los sacramentos de la iniciación cristiana." (R. GONZÁLEZ, La mistagogía en el Ritual de la Iniciación Cristiana dé Adultos, 382-383).

22. K. F. SMITS, Confirmation Re-examined: An Evolving Theology and Practice, en Worship 48 (1974) 22.

23. "Este pan que vosotros veis sobre el altar, santificado por la palabra de Dios, es el cuerpo de Cristo. [...] Si lo habéis recibido dignamente, vosotros sois eso mismo que habéis recibido. Dice, en efecto el Apóstol: Nosotros somos muchos, pero un solo pan, un solo cuerpo. He aquí cómo expuso el sacramento de la mesa del Señor: Nosotros somos muchos, pero un solo pan, un solo cuerpo. En este pan se os indica cómo debéis amar la unidad. ¿Acaso este pan se ha hecho de un solo grano? ¿No eran, acaso, muchos los granos de trigo? Pero antes de convertirse en pan estaban separados; se unieron mediante el agua después de haber sido triturados. Si no es molido el trigo y amasado con agua, nunca podrá convertirse en esto que llamamos pan. Lo mismo os ha pasado a vosotros: mediante la humillación del ayuno y el rito del exorcismo habéis sido como molidos. Llegó el bautismo, y habéis sido como amasados con el agua para convertiros en pan. Pero todavía falta el fuego, sin el cual no hay pan. ¿Qué significa el fuego, es decir, la unción con aceite? Puesto que el aceite alimenta el fuego, es el símbolo del Espíritu Santo [spiritus sancti est sacramentum]." (SAN AGUSTín, Serm. 227). La imagen que emplea el obispo de Hipona evoca lo que es la Iglesia - cuerpo de Cristo-y el proceso de iniciación por el cual se va construyendo como tal.

24. Hay que reconocer que la Iglesia cuanta con 'poco crédito' para nuestros contemporáneos. Esta confianza en la Iglesia sólo se podrá dar en la medida en que su testimonio 
comunidad eclesial ha de acoger a los candidatos, hacerse cargo y responsable de ellos -encargarse y responsabilizarse-, ser garante de su idoneidad, acompañarles a lo largo de su recorrido de fe y discernirla para purificarla. La comunidad cristiana concreta ha de ser, en definitiva, el lugar teológico del encuentro con el Dios Padre que se ha manifestado en su Hijo y que sigue actuando en ella movida por el Espíritu. Desde esta perspectiva, la relación entre el candidato y la comunidad cristiana ha de ser dinámico-dialogal: el uno pregunta y la otra da razón de su esperanza; la una testimonia y el otro se deja interpelar; el uno pide y la otra acepta; la una manifiesta y proclama el Evangelio y el otro lo va aceptando; el uno avanza en la conversión y la otra la discierne...

El objetivo de la iniciación cristiana puede ser formulado en los siguientes términos: conducir a los aspirantes a una pertenencia eclesial madura y responsable. No se trata meramente de una agregación sociológica sino de una participación plena en la vida de la Iglesia como sacramento de salvación para el mundo 25 .

"[...] la Iniciación cristiana es también un proceso socializador, que introduce gradualmente a las personas en un grupo y en una forma de vida, en este caso, la comunidad de los discípulos de Jesús, la Iglesia. [...] En todos los casos la meta [de la iniciación cristiana] es siempre la plena y consciente integración de los hombres en la comunión y en la misión de la Iglesia, cuerpo de Cristo y sacramento de salvación en medio del mundo. [...] La Iniciación está en el origen no sólo de la vida de la fe personal de cada uno de los cristianos, sino también de toda la comunidad eclesial, ya que es un proceso socializador. Por eso la atención que se presta a la Iniciación determina en gran medida la orientación pastoral de una Iglesia local, tanto a nivel parroquial como diocesano.

Por este motivo la pastoral de la Iniciación afecta no solamente a los que han de ser introducidos en la Iglesia, sino también a toda la comunidad eclesial. Es toda la Iglesia particular la que ha de interesarse por esta realidad y colaborar en ella [...]"26.

evangelizador sea auténticamente significativo para el hombre de hoy cf. J. MARTíN VELASCO, El reto de los alejados: ¿Un cambio de rumbo para la evangelización?, en Sal Terrae 78 (1990) 52.

25. "Pero tal vez haya tenido que producirse la situación de secularización para que los cristianos redescubramos este aspecto central del cristianismo que siglos de confusión acrítica de lo cristiano con lo social, lo político y lo cultural, y de identificación pura y simple del cristianismo con la pertenencia jurídica visible y la práctica cultural de la Iglesia, nos habían ocultado." (J. MARTÍN VELASCO, El reto de los alejados: ¿Un cambio de rumbo para la evangelización?, 49).

26. J. LÓPEZ, La iniciación cristiana, inserción en Jesucristo y en la vida de la Iglesia, 119-122. 
No podremos hablar de una iniciación cristiana plena sin una iniciación a la participación de la vida eclesial. La disociación entre fe e Iglesia tan típica de nuestro tiempo, era inconcebible en la teología de los padres: no se puede tener a Dios por Padre si no se tiene a la Iglesia como Madre27. La Iglesia no es sólo el lugar de nacimiento a la fe sino el lugar de su crecimiento y culminación ${ }^{28}$. La condición necesaria para que lo que se afirma en los gestos litúrgicos tenga autenticidad es ir incorporándose al misterio de la Iglesia, para ser miembros del cuerpo de Cristo ${ }^{29}$. Una Iglesia que pretende iniciar a otros en su misma fe ha de hacer memoria de cómo ha sido formada ella misma por medio de la iniciación. Una comunidad cristiana sólo puede ser Madre engendrando a nuevos hijos por medio del Espíritu si ella misma sigue siendo Hija de la iniciación que la ha ido configurando. El aspecto eclesial de la iniciación cristiana debe ayudar a la comunidad a enfrentarse a un principio que por simple, muchas veces es obviado: 'el itinerario por el que uno se hace cristiano es el camino por el que uno permanece siendo cristiano -la conversión- y el tránsito de la conversión, dura toda la vida, es comunitario y necesita de todos' 30 . Por eso, la iniciación cristiana está necesariamente vincu-

27. "Pero tiene que nacer [...] de las entrañas de la Iglesia, si es que nace para la herencia sempiterna de un Padre que es Dios. [...] Dios engendra por la Iglesia, no hijos que le sucedan, sino hijos que vivan perpetuamente con Él." (SAN AGUSTín, In Joh. 12, 5). El Concilio Vaticano II "enseña, fundado en la Escritura y en la Tradición, que esta Iglesia peregrina es necesaria para la salvación. Pues solamente Cristo es el mediador y el camino de salvación, presente a nosotros en su Cuerpo, que es la Iglesia, y Él, inculcando con palabras concretas la necesidad del bautismo (cf. Mc 16,16; Io 3,5), confirmó a un tiempo la necesidad de la Iglesia, en la que los hombres entran por el bautismo como puerta obligada. Por lo cual no podrían salvarse quienes, sabiendo que la Iglesia católica fue instituida por Jesucristo como necesaria, desdeñaran entrar o no quisieran permanecer en ella." (LG 14).

28. La Iglesia es hecha Madre "por la palabra de Dios fielmente recibida; en efecto, por la predicación y el bautismo engendra para la vida nueva e inmortal a los hijos concebidos por el Espíritu Santo y nacidos de Dios." (LG 64)

29. "En consecuencia, si vosotros sois el cuerpo y los miembros de Cristo, sobre la mesa del Señor está el misterio que sois vosotros mismos y recibís el misterio que sois vosotros. A lo que sois respondéis con el Amén, y con vuestra respuesta lo rubricáis. Se dice: 'El cuerpo de Cristo', y respondes. 'Amén.' Sé miembro del cuerpo de Cristo para que sea auténtico el Amén. [...] Traed a la memoria que el pan no se hace de un solo grano, sino de muchos. Cuando recibíais los exorcismos, erais como molidos; cuando fuisteis bautizados, como asperjados; cuando recibisteis el fuego del Espíritu Santo fuisteis como cocidos. Sed lo que veis y recibid lo que sois." (SAN AGUSTín, Serm. 272). San Agustín, en este texto, no está preocupado por las rúbricas litúrgicas sino por la realidad de la iniciación y por la autenticidad de la comunión eclesial.

30. W. HARMLESS, Augustine and the Catechumenate, 362. Aquí sólo acentuamos la exigencia de conversión del candidato pero, nunca hay que perder de vista que la presencia de catecúmenos recuerda constantemente a la Iglesia su necesidad de conversión cf. A. KAVANAGH, The norm of Baptism: the new Rite of Chistian Initiation of Adults, en Worship 48 (1974) 147. 
lada a la comunidad cristiana. No puede ser de otro modo. Desde esta vinculación se entiende que fuera de la Iglesia no pueda existir iniciación cristiana.

"Desde el momento de su ingreso en el catecumenado, la Iglesia abraza a los catecúmenos 'con cuidado y amor maternal, por estar vinculados a ella: son ya de la casa de Cristo'. Por eso, la comunidad cristiana 'debe ayudar a los candidatos y a los catecúmenos durante todo el período de la iniciación: en el precatecumenado, en el catecumenado y en el tiempo de la mistagogia'." (DGC 256)

La iniciación cristiana si quiere tener una oportunidad en nuestro tiempo necesita realmente trasparentar el elemento comunitario de manera visible y encarnada en comunidades cristianas que sean sacramento de la presencia del Espíritu del Resucitado. Por ello, las exigencias de la iniciación no sólo se dirigen hacia el candidato de la misma sino hacia el interior de la comunidad iniciante. Ella es no sólo agente de iniciación sino ámbito en el que se inicia a nuevos miembros. Por esta razón, la iniciación debe plantearle la exigencia de cambio, renovación y revitalización para acoger a los candidatos y a los que han sido iniciados en su seno y seguir, de esta manera, siendo Madre para todos. Si la iniciación debe suponer la regeneración de los candidatos, no menos exigible debe ser esa misma regeneración hacia el interior de la propia comunidad.

\section{III.2.- EI RICA como iniciación voluntaria a un grupo religioso}

No es nuestra intención hacer una exposición completa y detallada del RICA. Tan sólo pretendemos señalar aspectos, que consideramos más relevantes, de su primer capítulo a la hora de apuntar algunos elementos importantes en cualquier itinerario o proyecto de iniciación o re-iniciación cristiana. Queremos en este apartado recoger algunas de las aportaciones que nos ha ofrecido la fenomenología de la iniciación para aquilatar qué intenta conseguir el Ritual que nos ocupa.

\section{a) EI RICA como proceso ritual de paso}

El objeto de los ritos de paso es acompañar los cambios de estado o posiciones ${ }^{31}$, es "hacer que el individuo pase de una situación determinada a otra

31. Cf. V.TURNER, La selva de los símbolos, 104 y El proceso ritual, 101. 
situación igualmente determinada" 32 . A este respecto, podemos afirmar que el RICA es un ritual de paso pues intenta acompañar a los que "emprenden el camino de la fe y de la conversión [...proveyéndoles] de la ayuda espiritual para su preparación y para la recepción fructuosa de los sacramentos en el momento oportuno." (RICA 1). Es un ritual de paso en el sentido de que hace pasar a una persona de la fe y conversión iniciales a una plena inserción en el misterio de Cristo y de la Iglesia.

Según Van Gennep, los ritos de paso se caracterizan por una secuencia ritual que podemos apreciar en la alternancia de tiempos y grados como previamente hemos visto. Aún a riesgo de generalizar podemos afirmar que el RICA está compuesto por una serie de ritos de separación, tiempos de margen y ritos de agregación. Pero, este esquema se desdobla en el Ritual, pues los períodos de margen están suficientemente desarrollados como para constituir etapas cuasi-autónomas ${ }^{33}$.

El RICA, como ritual de paso, tiene ritos preliminares, liminares y postliminares. Los primeros son los que hacen referencia a la ruptura con el 'hombre viejo', el pecado, la idolatría... independientemente del grado o el tiempo en que se celebren. De esta manera, los ritos de separación del mundo anterior que más claramente destacan son los diferentes exorcismos y renuncias (cf. RICA 101). Los ritos liminares del RICA son los ejecutados durante los estadios o tiempos de margen. Así, durante el catecumenado, el tiempo liminar más amplio -que puede prolongarse durante años (cf. RICA 7 b, 103)-, la celebración de la liturgia de la Palabra, la catequesis y el ejercicio de la vida cristiana son los pilares de la liminaridad cristiana que tienen como objetivo hacer madurar la fe y conversión iniciales (cf. RICA 19, 106-108). Por último, los ritos postliminares son los agregación a la nueva condición. Habitualmente se considera que los sacramentos de iniciación cristiana, celebrados en la vigilia pascual, constituyen los ritos de agregación cristiana por excelencia, y así es. Pero, a lo largo del RICA las referencias a la agregación son continuas desde el rito de ingreso en el catecumenado (v.gr. ritos auxiliares ${ }^{34}$, introducción en el templo ${ }^{35}$, entrega de los Evangelios) ${ }^{36}$ hasta el rito de la elección (cf. RICA 146-147), pasando por referencias que hacen las oraciones de exorcismo durante el catecumenado ${ }^{37}$.

32. A. VAN GENNEP, Los ritos de paso, 13.

33. Cf. A. VAN GENNEP, Los ritos de paso, 21.

34. Arrojar sal o entrega de una cruz cf. RICA 89.

35. Cf. RICA 90.

36. Cf. RICA 93.

37. "[...] para que merezcan ser templos del Espíritu Santo" (RICA 113); “[...] para que sean santos y sin pecado en tu presencia" (RICA 114); “[...] para que, como hijos de la luz, sean miembros de tu santa Iglesia" (RICA 115); "[...] para que, unidos firmemente a Cristo, 
Podemos resumir diciendo que, el RICA es un ritual de paso en cuanto que marca la transición de una existencia lejos de la fe a otra vivida desde la fe en Cristo. Para ello, los candidatos han de olvidarse "de lo que queda atrás" y lanzarse "hacia el futuro" (RICA 373. 4) estimando todo como pérdida comparado con la nueva vida en Cristo.

\section{b) El RICA como proceso de iniciación}

Es cierto que el RICA es un rito de paso. Pero más ajustado es considerarlo, dentro de este tipo de ritos, como una subcategoría concreta: como un rito de iniciación ${ }^{38}$. Podemos afirmar que el RICA es un proceso de iniciación que tiene los elementos fundamentales de dichos procesos: ritos (preliminares, liminares y postliminares), enseñanzas, transmutación personal, agregación a una comunidad. El Ritual no presenta solamente la celebración de los sacramentos de iniciación sino los ritos del catecumenado que corresponde a la actividad misionera de la Iglesia (cf. RICA 2). En el RICA, la enseñanza no se reduce a lo meramente intelectual -exposición de dogmas- sino, sobre todo, a una instrucción pastoral que, sobre todo por medio de la catequesis, intenta llevar al convertido a una confesión de fe adulta que, a su vez, debe ser la causa de una transmutación existencial en todos los aspectos de su vida, al insertarse en el misterio de Cristo y de la vida de la Iglesia (cf. RICA 25). A lo largo del Ritual, de sus tiempos y grados, se intenta hacer una progresiva y auténtica iniciación. Los nombres que los candidatos van recibiendo -así como los libros en los que son inscritos- responden a los tiempos en lo que la fe va madurando paso a paso.

\begin{tabular}{|lll|}
\hline \multicolumn{1}{|c|}{ TIEMPO } & \multicolumn{1}{c|}{ NOMBRES } & LIBROS \\
\hline precatecumenado & simpatizante y candidato & \\
\hline catecumenado & catecúmeno $^{40}$ & \\
\hline $\begin{array}{l}\text { purificación e } \\
\text { iluminación }\end{array}$ & elegido, competente, iluminado $^{42}$ o postulante $^{43}$ & elegidos $^{44}$ \\
\hline mistagogia & neófito $^{45}$ & bautismos \\
\hline
\end{tabular}

sean contados entre sus discípulos aquí en la tierra y puedan alegrarse de ser reconocidos por Él en el cielo" (RICA 117); [...] para que [...] se hagan dignos templos del Espíritu Santo" (RICA 373. 1); [...] consigan la dignidad del pueblo sacerdotal y se alegren con el gozo incontenible de la nueva Jerusalén" (RICA 373.2).

38. Cf. A. VAN GENNEP, Los ritos de paso, 76. 
Tres son los ritos que pueden ser considerados centrales en el RICA como rituales del umbral en la progresiva agregación a la comunidad cristiana: el de acceso al catecumenado, el de la elección o inscripción del nombre y, por último, los sacramentos de iniciación cristiana. Cada uno de estos rituales de umbral marca, a modo de escalones, el acceso a un tiempo en el que se profundiza la fe y conversión previa. De esta manera, la estructura iniciática puede ser considerada ascendente -al igual que toda vida cristiana- pero siempre sometida a la dialéctica del 'ya pero todavía no'. Por ello, uno de los aspectos que diferenciará la iniciación cristiana es su tendencia escatológica, que nunca puede perderse de vista si no es a riesgo de una ontologización paralizante.

Dentro del catecumenado, entendido en su sentido más amplio -catecumenado en sentido estricto (desde la admisión al mismo hasta el rito de elección) junto con el tiempo cuaresmal (de purificación e iluminación-, debe profundizarse y elaborarse la experiencia de muerte (ruptura y separación respecto al antiguo modo de vida alejado de la experiencia de fe y de la Igle-

39. Cf. RICA 12. Durante el rito de admisión al catecumenado a los 'simpatizantes' se les designa "candidatos" (cf. RICA 69; 71; 72-77; 79-81; 83-84).

40. Se les empieza a llamar "catecúmenos" en el rito de entrada a partir de la signación (cf. RICA 87), aunque en las rúbricas del rito de la signación ya se refiere a ellos como "catecúmenos" (cf. RICA 85).

41. Después del rito de entrada al catecumenado se han de inscribir los nombres de los catecúmenos en un libro destinado a tal propósito (cf. RICA. 17).

42. Desde el día de la elección y de su admisión para recibir los sacramentos de iniciación, los catecúmenos reciben el nombre de 'elegidos', 'competentes', 'iluminados' o cualquier otra denominación que más se acomode a la comprensión de todos dependiendo de la lengua (cf. RICA 24). A pesar de esto, el ritual les sigue llamando catecúmenos (cf. RICA $152 ; 154 ; 157 ; 162 ; 164 ; 181$ ). Puesto que la unción con el óleo de los catecúmenos se puede tener el Sábado Santo antes o después del rito de la recitación del credo, separadamente de él (cf. RICA 206) o bien en la vigilia Pascual entre las renuncias y la profesión de fe (cf. RICA 218). El Ritual afirma: "Con la ceremonia de la 'elección' concluye el catecumenado mismo [...]" (RICA 134). En todo lo anterior, podemos detectar que el tiempo del catecumenado es, en el sentido de V. Turner, una etapa inter-estructural definida por la ambigüedad.

43. Cf. RICA 153; RICA 155.

44. No se dice expresamente que deba existir un libro oficial de elegidos, pero por el contexto, podría deducirse o, al menos, admitirse su existencia (cf. RICA 146).

45. Cf. RICA 37-40; 225-226; 229; 231-236; 238-239. El tiempo de la mistagogia termina con el tiempo pascual (cf. RICA 237), pero el Ritual sigue llamando 'neófitos' a los recién bautizados más allá de ese tiempo: "En el aniversario del Bautismo sería de desear que los neófitos se reunieran de nuevo para dar gracias a Dios, y para cambiar entre sí sus experiencias personales y para renovar las energías espirituales." (RICA 238). "Para comenzar su trato pastoral con los nuevos miembros de su Iglesia, cuide el Obispo [...] que al menos una vez al año, en cuanto sea posible, se reúna con los neófitos últimamente bautizados y presida la celebración de la Eucaristía [...]" (RICA 239). 
sia) como las de resurrección (descubrimiento más profundo de la fe, la esperanza, la caridad así como la experiencia gozosa de crecer en esta nueva forma de vida al participar de la comunidad cristiana). El lenguaje dogmático es el punto referencial objetivo para ello, pero el litúrgico-simbólico así como el existencial son necesarios para aunar y encontrar significativo el lenguaje eclesial que los candidatos deben ir aprendiendo. Para ello, es necesario que los lazos que la comunidad cristiana iniciadora tienda a los catecúmenos sean reales, significativos, no reducidos a una asamblea litúrgica anónima ${ }^{46}$. La reducción a lo formal puede esterilizar el proceso de iniciación reduciéndolo a un mero rito de paso. Los ministerios y oficios para la iniciación cristiana (cf. RICA 41-48) deben saber replantearse su función para que los candidatos perciban, de manera viva, que la iniciación cristiana no es la introducción en tradiciones -en la fe muerta de personas vivas- sino en la Tradición -en la fe viva de personas que han muerto- que se remonta a Cristo muerto y resucitado $^{47}$. Para ello, toda la comunidad inmediata de referencia debe saber vivir y desarrollar sus funciones kerigmática, litúrgica y diakónica al implicar, tanto a los fieles que la constituyen, como a los candidatos que acceden a la iniciación.

El RICA como proceso de iniciación debe tener una estructura circular para, posteriormente, abrirse a la historia redimida por la Encarnación y proyectarse hacia el esjaton del Dios de Jesucristo. En el tiempo preliminar se ha de propiciar la experiencia primera y básica de fe-conversión como separación y ruptura con el marco existencial en el que vivía el candidato. El tiempo del catecumenado -incluyendo el de purificación e iluminación- debe constituirse como un auténtico tiempo liminar o de margen para profundizar y purificar la conversión y fe iniciales. Por último, los sacramentos de inicia-

46. "Las más bellas ceremonias pascuales tendrán un mañana de desencanto si los nuevos bautizados se topan con el anonimato de una masa de cristianos que permanecen extraños a la acción catecumenal." (M. DUJARIER, Iniciación cristiana de los adultos, 33).

47. Cf. W. J. REEDY (ed.), Becoming a Catholic Christian. A symposium on Christian Initiation, William H. Sadlier, New York 19813, 178. La idea es de Jaroslav Pelikan cf. W. HARMLESS, Augustine and the Catechumenate, 346. La iniciación introduce al candidato "en una tradición viva, como parte viva y activa de ella; toma posesión del patrimonio de la comunidad y su tradición y asume un papel efectivo en ella." (M. A. MEDINA, La iniciación como proceso de madurez socio-religiosa. Breve recorrido por la historia, 18). "Antes que hablar de 'las' entregas ('traditiones'), recordemos que la maternidad de la Iglesia se ejerce por 'la' entrega ('traditio'). Esta no es solamente un objeto que transmitir, el tesoro familiar que son sus costumbres, sino también y ante todo la acción misma de la transmisión realizada por la comunidad familiar. Por experiencia, sabemos muy bien que la tradición es el lazo que nos une a nuestros predecesores de una manera vital, al mismo tiempo que existencial y afectiva. Es como el medio sagrado en el que se forma e informa el individuo, desde la cuna hasta la tumba." (M. DUJARIER, Iniciación cristiana de los adultos, 132). 
ción cristiana junto con el tiempo de la mistagogia han de significar lo que realmente ha acontecido en los iniciados: la acogida por parte de los neófitos del don gratuito de Dios que regenera tan radicalmente a la persona y la inserta en la comunidad cristiana y en el mundo de forma esencialmente diferente a como comenzó el proceso iniciático, es decir, como fiel. Esta regeneración que, desde el ámbito teológico, tradicionalmente se ha atribuido a los sacramentos, habría que decir que es causada, existencialmente, por todo el proceso de iniciación cristiana, momentos sacramentales incluídos.

\section{c) EL RICA como 'iniciación voluntaria a un grupo religioso'}

Ya hemos visto en el capítulo anterior que, según M. Eliade, hay tres tipos diferentes de iniciación. La iniciación cristiana no es a un grupo de edad concreto ni tampoco obligatoria para todos los miembros de una determinada sociedad; es, por tanto, voluntaria. Esta es la razón por la cual consideramos que la iniciación cristiana que presenta el RICA no puede ser considerada como una 'iniciación tribal o de pubertad'.

"En la tradición cristiana no hay ningún símbolo o ceremonia especial-
mente asociados al paso de la infancia a la madurez propia del adulto. Al
mismo tiempo, la maduración en la fe cristiana, o iniciación entendida
como conversión y decisión personales, es una necesidad en esa etapa de
la vida. Es ésta una etapa en que se ha de adquirir una identidad personal
y un sentido de adhesión a la sociedad de los adultos. Es el momento en
que la persona ha de optar entre la aceptación o el rechazo de los símbo-
los y significaciones de su cultura. Se trata de una experiencia gravemente
traumática, sobre todo hoy, cuando la sociedad y la cultura atraviesan un
proceso de desintegración. Podríamos preguntarnos si en la historia cris-
tiana hay algo capaz de fortalecer a un joven que se encuentra en este mo-
mento de transición"48.

Tampoco creemos que pueda ser considerada como una iniciación a una 'vocación mística' porque tiene un destinatario ordinariamente individual y los elementos extáticos juegan un papel de primer orden. Por ello, la iniciación cristiana responde al esquema de lo que Eliade llamaría iniciación a una 'sociedad secreta' pero con su propia peculiaridad, por lo que nosotros preferimos designar como iniciación a un 'grupo religioso'.

48. D. POWER, La odisea del hombre en Cristo, 277. 
El RICA es una iniciación que pretende profundizar la experiencia de fe de una persona que, libre y voluntariamente ${ }^{49}$, la acoge como don de Dios ofrecido por mediación de la Iglesia. De ahí, que la iniciación cristiana sea esencialmente sacramental en el sentido de introducción en el gran sacramento que es la Iglesia. Con todo - a diferencia del modelo de iniciación a una 'sociedad secreta'- esta iniciación no tiene como objetivo segregar al candidato del mundo social en el que vivía para agregarle a 'otro mundo', sino el de agregarle al mismo habiéndolo transformado en una persona nueva mediante su inserción en el misterio de Cristo y de su Iglesia. La iniciación cristiana que presenta el RICA supone, ciertamente, rupturas con un estilo de vida, pero, al mismo tiempo, intenta regenerar al candidato para que vuelva al mundo y, en él, viva esa regeneración como miembro del Cuerpo de Cristo con todo lo que ello implica ${ }^{50}$.

\section{III.3.- Estructura ternaria de la iniciación en el RICA ${ }^{51}$}

Una de las aportaciones más importantes de Van Gennep es el concepto de 'secuencia ritual' en los procesos rituales de paso e iniciación ${ }^{52}$. Contemplar un rito desgajado del conjunto del que forma parte es, de alguna manera, perder parte de su significado profundo. Por eso, para descubrir el significado profundo de los diferentes gestos que propone en RICA es necesario situarlos dentro de la secuencia ternaria de los procesos de iniciación en cuanto rituales de paso. La secuencia ritual prueba, según Van Gennep, que el orden en que los ritos se suceden y ejecutan es un elemento religioso de importancia capital.

De esta manera, el primer grado de la iniciación cristiana -el rito de entrada en el catecumenado- está compuesto por ritos de separación del medio habitual y de agregación al medio sagrado. El tiempo de margen -como tiem-

49. "El Ritual de la Iniciación Cristiana, que se describe a continuación se destina a los adultos que, al oir el anuncio del misterio de Cristo, y bajo la acción del Espíritu Santo en sus corazones, consciente y libremente buscan al Dios vivo y emprenden el camino de la fe y de la conversión." (RICA 1)

50 . En el proceso de iniciación cristiana 'no todo vale' pues no se trata de hacer prosélitos cf. J. MARTÍN VELASCO, El reto de los alejados: ¿Un cambio de rumbo para la evangelización?, 46-47.

51. Para un buen resumen del primer capítulo del RiCA cf. A. KAVANAGH, Christian initiation of adults: the rites, en Worship 48 (1974) 318-335. Un comentario más extenso y desarrollado lo hace M. DUJARIER, Iniciación cristiana de los adultos. Comentario histórico y pastoral del nuevo Ritual, Ed. Desclée de Brouwer, Bilbao 1986.

52. Cf. A. VAN GENNEP, Los ritos de paso, 102; 106-109. 
po 'sagrado'- es un espacio interestructural 'ambiguo'. Por último, desde el segundo al tercer grado del RICA -tiempo de purificación-iluminación y sacramentos de iniciación cristiana- contempla ritos de separación del catecumenado así como de reintegración al medio habitual. Esta vuelta al mundo del que procedía el candidato no la lleva a cabo 'la misma persona' que comenzó el proceso iniciático sino una diferente, transmutada y regenerada con una cualidad religiosa especial ${ }^{53}$.

\section{a) Separación 54}

Para que exista auténtica separación, se requiere en el candidato "una vida espiritual inicial y los conocimientos fundamentales de la doctrina cristiana" (RICA 15), es decir, una fe y conversión inicial, la voluntad de cambiar de vida, haber empezado el trato con Dios en Cristo y una primera experiencia de trato con los cristianos ${ }^{55}$. Si esta conversión, fe y eclesialidad inicial no están presentes, el catecumenado como tiempo de margen no puede empezar. El catecumenado sólo podrá hacer madurar lo que, de manera incipiente, ya debe existir en el candidato: la fe.

"De gran importancia es el rito llamado 'Entrada en el Catecumenado', porque entonces los candidatos se presentan por primera vez y manifiestan a la Iglesia su deseo, y ésta, cumpliendo su deber apostólico, admite a los que pretenden ser sus miembros." (RICA 14)

Las disposiciones para entrar en el catecumenado deben ser discernidas por la Iglesia según indicativos externos (cf. RICA 16). El tiempo del precatecumenado ha debido constituirse, no como un tiempo vacío, para que el

53. Cf. A. VAN GENNEP, Los ritos de paso, 95.

54. Hay diferencias importantes entre la iniciación de infantes y la de adultos. En términos jungianos, podríamos afirmar que el paradigma iniciático de infantes da una mayor importancia a los aspectos 'femeninos' del cristianismo (generación, filiación, vocación divina, crecer hacia el futuro, adopción-filiación, seno) mientras que la iniciación de adultos despliega, en mayor medida, los elementos 'masculinos' del universo simbólico cristiano (regeneración, hermandad, decisión personal, romper con el pasado, muerte-resurrección, tumba).

55. "Para dar este paso se requiere en los candidatos una vida espiritual inicial y los conocimientos fundamentales de la doctrina cristiana: a saber, la primera fe concebida en el tiempo del 'precatecumenado', la conversión inicial y la voluntad de cambiar de vida y de empezar el trato con Dios en Cristo, y, por tanto, los primeros sentimientos de penitencia y el uso incipiente de invocar a Dios y hacer oración, acompañados de las primeras experiencias en el trato y espiritualidad de los cristianos." (RICA 15) 
simpatizante pueda ir dando los pasos que le conduzcan a ir separándose de su vida previa ${ }^{56}$. El rito de entrada en el catecumenado requiere que el candidato sea avalado por algún fiel que "le conozca, le ayude y sea testigo de sus costumbres, de su fe y de su voluntad." (RICA 42). Si no ha existido un tiempo de precatecumenado es muy difícil que algún miembro de la comunidad pueda cumplir este cometido. Ya hemos señalado que la separación de los candidatos es de vital importancia en cualquier iniciación. En la iniciación cristiana a esta separación hay que llamarla por su nombre: conversión. A este respecto las palabras de uno de los estudiosos más preclaros en el catecumenado afirma: “[...] las lecciones de la historia nos deben instruir. ahora bien, la evolución de la práctica catecumenal de los primeros siglos es sintomática. El período más bello fue aquel en el que el umbral de la admisión a la catequesis propiamente dicha ha sido respetado, es decir, mientras no se admitía al catecumenado más que a gente efectivamente convertida, bien decididos a seguir a Cristo. A partir del momento en el que el rito de admisión fue dado a candidatos insuficientemente convertidos, la institución catecumenal estaba tocada en su raíz. Del mismo modo, el debilitamiento de las exigencias del acceso al bautismo hizo bajar la calidad de vida evangélica de las comunidades. Allí donde el bautismo no se percibe ni se vive como el inicio de un nuevo estilo de vida, es muy difícil resistir al inevitable peligro de sincretismo.

Por lo tanto, nunca se subrayará suficientemente que la revalorización de la iniciación cristiana está condicionada, a la vez, por la restauración de los dos umbrales que son la entrada en el catecumenado y el llamamiento decisivo al bautismo, y por la seriedad con la cual los convertidos serán admitidos a franquear estos dos umbrales, especialmente el primero" 57 .

Aquí está una de las claves más importantes de la iniciación cristiana: si no hay fe inicial, cualquier intento de edificación de una personalidad cristiana estará avocada, casi indefectiblemente, al fracaso. Si no hay separación previa, es decir, conversión, no se puede comenzar en absoluto un proceso de iniciación cristiana ${ }^{58}$. En el rito de entrada, se presenta el candidato que pide la fe a la Iglesia ${ }^{59}$. El presidente de la asamblea declara que el camino del Evangelio y de la fe se abre ante los candidatos a la iniciación "para que tengáis la

56. "Antes de que los candidatos sean admitidos entre los catecúmenos [...] espérese algún tiempo, el conveniente y necesario en cada caso concreto, para investigar los motivos de la conversión, y para purificarlos, si es necesario." (RICA 69).

57. M. DUJARIER, Iniciación cristiana de los adultos, 29.

58. Cf. M. DUJARIER, Iniciación cristiana de los adultos, 43-46.

59. Cf. RICA 75. Los diferentes ritos que componen el rito de entrada en el catecumenado se realizan en torno a tres 'lugares': fuera del templo, en el umbral, y dentro del 
vida eterna" (RICA 76) y, a continuación, después de manifestar que están dispuestos a empezar ese camino, se dirige a la comunidad para que manifiesten su compromiso de ayudar a los candidatos a buscar y seguir a Cristo ${ }^{60}$. Los tres ritos siguientes ${ }^{61}$ son de separación (exorcismo y renuncia a los cultos paganos) ${ }^{62}$, de separación y agregación a la vez (signación de la frente y de los sentidos) ${ }^{63}$ y de agregación (imposición del nuevo nombre, ritos auxiliares, introducción en el templo y la celebración de la Palabra) ${ }^{64}$.

Este primer rito supone una agregación al grado de los catecúmenos, no al de los fieles, pero de alguna manera es también una agregación a la Iglesia si tenemos en cuenta el estatuto, no del todo clarificado, de los catecúmenos dentro de la comunidad eclesial:

"Porque desde ese momento los catecúmenos (a los que ya abraza como suyos la santa madre Iglesia con amor y cuidado maternal, por estar vinculados a ella) son ya de "la casa de Cristo"” (RICA 18).

Al ser un rito de agregación eclesial, los catecúmenos ya pueden participar de ciertos 'privilegios' que no se concedía a los simpatizantes que se encontraban en estatus anterior. De esta manera pueden contraer matrimonio y

templo. Para una exposición de la estructura de este rito cf. M. DUJARIER, Iniciación cristiana de los adultos, 46-50.

60. Cf. RICA 77.

61. "El primer grado era el de los catecúmenos; la entrada a este grado incluía: $1^{\circ}$ la exsuflación, con una fórmula de exorcismo; $2^{\circ}$, el signo de la cruz sobre la frente; $3^{\circ}$, la administración de sal exorcizada. Como se ve, estos ritos no son ya directos como entre algunos semicivilizados, sino animistas, como entre ciertos negros y amerindios; el primer rito es un rito de separación; el segundo separa y agrega a la vez y equivale al marcado (sfragh) de los misterios griegos y del cristianismo primitivo; el tercer rito es un rito de agregación, en virtud sobre todo de la oración que le acompaña." (A. VAN GENNEP, Los ritos de paso, 107). Está describiendo el bautismo de adultos según el manual sacramental de Gelasio.

62. Cf. RICA 78-82.

63. Cf. RICA 83-87. "La señal de la cruz, al comienzo de la celebración [del bautismo], señala la impronta de Cristo sobre el que le va a pertenecer y significa la gracia de la redención que Cristo nos ha adquirido por su cruz." (CEC 1235). Las palabras que el celebrante dirige a los candidatos pone de manifiesto que esta signación es un rito de agregación: "Ahora, pues, queridos candidatos, acercaos con vuestros padrinos para recibir la señal de vuestra nueva condición." (RICA 83). La agregación al catecumenado por medio de la signación se pone también de manifiesto en estas otras palabras: "[...] ahora juntamente con vuestros catequistas y padrinos os signaré a vosotros con la señal de la cruz de Cristo para indicar vuestra entrada en el catecumenado; $y$ toda la comunidad os acogerá con su amor y os ayudará con su auxilio." (RICA 84).

64. Cf. RICA 88-95. Mediante la recepción del nombre, la persona es individualizada y agregada a la sociedad. Aunque la imposición del nombre es un rito de agregación también se podría considerar como de separación respecto de la antigua condición. Este rito, dentro de la iniciación cristiana puede realizarse en este momento o bien como parte de los 
recibir exequias cristianas (cf. RICA 18) ${ }^{65}$. Como primera muestra de que el proceso de iniciación cristiana es una agregación a la Iglesia se dice: "Es de desear que toda la comunidad cristiana [...] tenga parte activa en la ceremonia." (RICA 70). La comunidad debe estar presente, de una u otra forma, en la iniciación cristiana en cuanto que ella es la que inicia y la que acoge. El padrino que presenta al candidato a la Iglesia debe desempeñar un papel determinante. Al ser el padrino un miembro de la comunidad que da testimonio y presenta al candidato su calidad cristiana será de suma importancia para que la iniciación de su ahijado pueda llegar suponer una regeneración de su vida y de la comunidad.

\section{b) Margen}

El tiempo del catecumenado es, fenomenológicamente hablando, el tiempo liminar por excelencia del proceso de iniciación cristiana ${ }^{66}$. No tiene

ritos de preparación inmediata (cf. RICA 203-205). Se trata de imponer un nombre cristiano, un nombre que admita un sentido cristiano o, en caso de mantener el mismo nombre, "explicar la significación cristiana del nombre que le dieron sus padres." (RICA 88; cf. 203; 205). "Si existieran algunas costumbres locales aptas para significar la entrada en la comunidad, v.gr. arrojar sal u otro acto simbólico [...] se pueden añadir antes o después del ingreso en el templo." (RICA 89). Esta entrada material es, posiblemente, el rito que más gráficamente manifiesta su carácter de agregación. Hay que recordar que, al ser parte del rito de entrada en el catecumenado, no supone una agregación plena como se aprecia en el momento de ser despedidos los catecúmenos antes de la liturgia eucarística. Al ser agregados al grado de los catecúmenos tienen acceso a la Palabra de Dios que les servirá de alimento y así poder crecer en la fe: "entrad en la iglesia, para que tengáis parte con nosotros en la mesa de la palabra de Dios." (RICA 90). La participación en la liturgia de la Palabra será, a lo largo del catecumenado, una constante. Por ello, el Ritual apunta la necesidad de que se muestre la dignidad de la palabra de Dios (cf. RICA 91) y de elegir "lecturas acomodadas a los nuevos catecúmenos" (RICA 92).

65. Aunque los catecúmenos pueden contraer matrimonio cristiano, necesitan dispensa de disparidad de culto. Este requisito le parece anormal a M. Dujarier pero se entiende bien desde el momento en que tenemos en cuenta que los catecúmenos, habiendo sido agregados de alguna manera a la Iglesia, están en una etapa esencialmente ambigua como ya hemos descrito siguiendo a V. Turner cf. M. DUJARIER, Iniciación cristiana de los adultos, 177 , nota 28. "It is clear [...] that a catechumen is neither a non-Christian nor a nonmember of an ecclesial community, but a Christian in fieri and a member of the church local and universal." (A. KAVANAGH, The norm of Baptism: the new Rite of Chistian Initiation of Adults, 147).

66. "[...] liminality is trans-rational, or should I say 'pre-rational,' and liturgy needs to partake of this element. (Lest I be misunderstood. I am not saying that is anti-rational.) What I mean by this is that we participate in those dimensions of life which are not controlled by reason alone; and we become aware of experience which is not filtered through conceptual or even commonsense systems, as is true of the vast majority of the thoughts we are willing to acknowledge as our own." (U.T. HolMES, Liminality and liturgy, 395). 
una duración determinada a priori pues su objetivo es la maduración de la fe y conversión de los catecúmenos (cf. RICA 98). Dicho en otros términos: el catecumenado es "la formación de la vida cristiana en su integridad" y "el adiestramiento debidamente prolongado" para que los catecúmenos sean "iniciados convenientemente en los misterios de la salvación y en la práctica de las costumbres evangélicas y en los sagrados ritos" (RICA 98).

"El catecumenado es un tiempo prolongado, en que los candidatos reciben la instrucción pastoral y se ejercitan en un modo de vida apropiado, y así se les ayuda para que lleguen a la madurez las disposiciones de ánimo manifestadas a la entrada." (RICA 19).

Para conseguir esta madurez, se utilizan cuatro caminos: la catequesis apropiada, el ejercicio de la práctica de la vida cristiana, los ritos litúrgicos y la cooperación en la evangelización de la Iglesia (cf. RICA 19). La iniciación cristiana, como ya hemos apuntado, trata de forjar la identidad cristiana en relación a los tres rasgos que la caracterizan. Por medio del catecumenado, como tiempo de margen, los catecúmenos "son introducidos en la vida de la fe, de la liturgia y de la caridad del pueblo de Dios." (RICA 98).

"Puesto que por la gracia de Dios el nuevo convertido emprende un camino espiritual por el que, participando ya por la fe del misterio de la muerte y de la resurrección, pasa del hombre viejo al nuevo hombre perfecto según Cristo. Trayendo consigo este tránsito un cambio progresivo de sentimientos y de costumbres, debe manifestarse con sus consecuencias sociales y desarrollarse poco a poco durante el catecumenado." (AG 13; citado por el RICA 19.2).

Este es pues el objetivo del catecumenado como etapa liminar: el tránsito del hombre viejo al hombre nuevo configurado según Cristo. Para conseguir este tránsito, no se puede fijar a priori la prolongación necesaria para que se produzca, pues depende de muchas circunstancias entre las que destacamos la gracia de Dios, la organización de todo el catecumenado, la cooperación de cada catecúmeno y la ayuda de la comunidad local (cf. RICA 20).

El catecumenado, como etapa de margen, tiene un desarrollo amplio en el esquema de la iniciación cristiana típica y una cierta 'autonomía' aunque nunca se puede separar de la secuencia de la que forma parte. En este sentido, el RICA afirma: 
"Durante los años que dura el catecumenado a partir del primer grado catequético, los pasos de un grado a otro, por los que van ascendiendo progresivamente los catecúmenos, pueden simbolizarse o significarse a veces con algunos ritos." (RICA 103).

Desde el rito de entrada, los catecúmenos han sido agregados, de alguna manera, a la Iglesia, aunque todavía no plenamente. Pueden participar con los fieles en la liturgia de la palabra, pero son despedidos antes de comenzar la liturgia eucarística. Quizá este gesto no sea demasiado elocuente en nuestros días, pero, de alguna manera, la práctica del arcano remite al misterio que no se muestra sin una previa iniciación en él67.

A pesar de que sería conveniente revisar la cosmovisión que subyace en muchas de las oraciones del Ritual, los exorcismos menores celebrados durante el catecumenado (cf. RICA 109-118) han de servir para mostrar a los catecúmenos "la verdadera condición de la vida espiritual, la lucha entre la carne y el espíritu, la importancia de la renuncia para conseguir las bienaventuranzas del reino de Dios, y la necesidad constante del divino auxilio" (RICA 101). El catecumenado se constituye, de esta manera, como un momento de prueba donde los iniciandos han de hacer frente a las dificultades de la iniciación en la vida cristiana, no de manera heroica, sino desde la gracia de Dios. Los exorcismos simbolizan la separación progresiva del catecúmeno del mundo no cristiano ${ }^{68}$ para que pueda producirse la agregación deseada ${ }^{69}$. El

67. "K. Rahner era uno de los que se habían involucrado en esta discusión [sobre la retransmisión televisiva de la misa]. En aquellos momentos [1959] él era estricto contra la misa en televisión. Según él, la plena y detallada celebración de la eucaristía es un objeto preferente de aquel pudor metafísico que prohíbe hacer de este acontecimiento una publicidad asequible, indiferente y repartida a cualquiera. Se representa ante mis ojos lo que, entre tanto, se puede experimentar en la conocida como religión electrónica: la lesión más masiva de este pudor metafísico. [...] Igual que había dicho, antes que él, Dietrich Bonhoeffer - 'a la palabra tiene acceso incluso el no creyente, pero al sacramento no' (1937)-, Rahner recuerda también aquella antigua tradición eclesiástica a la que se conoce como la disciplina del arcano." (J. B. METZ, La trampa electrónica. Notas teológicas sobre el culto religioso en la televisión, en Concilium 250 (1993) 1038). Cf. M. DUJARIER, Iniciación cristiana de los adultos, 197-198. Respecto a la disciplina del arcano y la pedagogía del silencio cf. W. HARMLESS, Augustine and the Catechumenate, 363-64.

68. "[...] aparta de ellos todo espíritu maligno" (RICA 113); "[...] que alejes de estos siervos tuyos la incredulidad y la duda (el culto de los ídolos y la magia, los encantamientos y el espiritismo), el ansia de dinero y los halagos de las pasiones, las enemistades y discordias y cualquier forma de maldad" (RICA 114); "[...] líbralos con tu poder de todos los males y de la esclavitud del enemigo; arranca de ellos el espíritu de la mentira, de la codicia y de la maldad" (RICA 115); “[...] se conserven inmunes del espíritu de codicia y avaricia, de sensualidad y de soberbia" (RICA 116).

69."[...] para que merezcan ser templos del Espíritu Santo" (RICA 113);“ [...] para que sean santos y sin pecado" (RICA 114); "Recíbelos en tu reino, ábreles los ojos a tu Evange 
rito de la unción de los catecúmenos -al unirse con algún exorcismo- (cf. RICA 130-132) subraya, sobre todo, el poder de Cristo que fortalece al catecúmeno en sus pruebas. Las bendiciones durante el catecumenado (cf. RICA 119-124) tienen, como los exorcismos, dos polaridades que miran a la regeneración espiritual ${ }^{70}$ y la agregación eclesial ${ }^{71}$.

La cuaresma también puede ser considerada como un tiempo de margen de retiro y preparación espiritual inmediata a la recepción de los sacramentos de iniciación. Como tiempo 'autónomo' comienza con el rito de elección o inscripción del nombre de los elegidos para participar en la iniciación sacramental. Este rito, como ya hemos señalado, puede ser interpretado o como de separación (respecto del catecumenado propiamente dicho) o de agregación al tiempo de iluminación y purificación.

A lo largo del tiempo cuaresmal, tres tipos de ritos son los que progresivamente marcan la cercanía de la vigilia pascual y la recepción de los sacramentos: los escrutinios ${ }^{72}$, las entregas ${ }^{73}$ y los ritos de preparación inmediata ${ }^{74}$. Los tres escrutinios cuaresmales se encaminan a purificar los corazones de los elegidos, rectificar sus intenciones y mover su voluntad para que se unan más profundamente a Cristo (cf. RICA 154)75. Las entregas (del símbolo y de la oración dominical) pretenden iluminar más profundamente por dos de las an-

lio, para que, como hijos de la luz sean miembros de tu santa Iglesia, den testimonio de la verdad y practiquen, según tus mandamientos, las obras de misericordia" (RICA 115); “[...] para que, unidos firmemente a Cristo, sean contados entre sus discípulos aquí en la tierra y puedan alegrarse de ser reconocidos por Él en el cielo" (RICA 117); "[...] concédeles que merezcan participar de tus sacramentos en la tierra, y gozar de tu compañía eterna en el cielo" (RICA 118).

70 "[...] regenerados en la fuente del bautismo" (RICA 121); "[...] la regeneración espiritual” (RICA 122); "[...] para que progresen día a día en toda virtud, reciban en el momento oportuno la regeneración para el perdón de los pecados" (RICA 124).

71 "[...] sean contados entre los miembros de tu Iglesia" (RICA 121); “[...] merezcan [...] la entrada en la comunión de la Iglesia" (RICA 122); “[...] agrégalos a tu Iglesia" (RICA 123).

72 Cf. M. DUJARIER, Iniciación cristiana de los adultos, 115-129. Puesto que este autor reflexiona desde la praxis pastoral en África las reflexiones en torno a la cosmovisión de aquellos pueblos es acertada cf. especialmente las páginas 126-127. Con todo, el lenguaje que utiliza el Ritual está muy lejos de la cosmovisión occidental (post)moderna. Otros autores se refieren a los escrutinios como discernimiento "para verificar la autenticidad del proceso realizado por el catecúmeno: es decir, si realmente ha pasado de la sed al agua de la vida [...]; de la ceguera a la luz [...]; de la muerte a la vida [...]" (J. LóPEZ SÁEZ, Catecumenado e inspiración catecumenal, 288). Para las diferencias entre discernimiento y evaluación de la catequesis cf. J. LóPEZ SÁEZ, Catecumenado e inspiración catecumenal, 290.

73 Cf. M. DUJARIER, Iniciación cristiana de los adultos, 131-152.

74 Cf. M. DUJARIER, Iniciación cristiana de los adultos, 168-170.

75 "Los 'escrutinios' [...] se dirigen a estos dos fines anteriormente mencionados: a saber, a descubrir en los corazones de los elegidos lo que es débil, morboso o perverso para sanarlo; y lo que es bueno, positivo y santo para asegurarlo. Porque los escrutinios se orde 
tiguas señas de identidad cristianas: la profesión de fe y la oración del Señor ${ }^{76}$. Por último, los ritos de preparación inmediata son: la devolución del símbolo (cf. RICA 194-199), el rito del effetá (cf. RICA 200-202); la elección del nombre cristiano en caso de no haberse tenido en la entrada al catecumenado (cf. RICA 203-205) y, si no se tiene en la vigilia pascual, la unción con el óleo de los catecúmenos antes de la recitación del símbolo -como preparación-o después -como su ratificación- (cf. RICA 206-207)77.

\section{c) Agregación}

Los sacramentos de iniciación cristiana son el momento culminante de la iniciación, pero no agotan por sí mismos toda la iniciación. Una excesiva ontologización de los sacramentos les priva de su aspecto dinámico-existencial. No hace falta hacer una argumentación excesivamente complicada para constatar que muchos (quizá demasiados) cristianos han recibido los tres sacramentos de iniciación pero no están realmente iniciados en la vida cristiana. Sin sacramentos no hay iniciación cristiana, pero los sacramentos no aseguran la iniciación cristiana. Aquí se pone de manifiesto el desfase entre el deber ser y el ser, entre la teología y la pastoral de la iniciación. Intentar unir o, al menos, acercar estas polaridades debe ser el objetivo de cualquier proceso de iniciación cristiana que pretenda ser auténtico.

La vigilia pascual-memorial del paso del Señor para liberar a su pueblo, del paso de la esclavitud a la libertad, del paso de la muerte de Jesucristo a su resurrección- es la noche más adecuada y que mejor marco simbólico proporciona para la iniciación cristiana ${ }^{78}$. La liturgia de esta noche es rica en todo tipo de simbolismos y está compuesta por cuatro partes: liturgia de la luz, de la Palabra, del agua y, por último, la liturgia eucarística. La historia de la salvación es el eje que guía toda esta liturgia.

nan a la liberación del pecado y del diablo, y al fortalecimiento en Cristo, que es el camino, la verdad y la vida de los elegidos." (RICA 25.1). Para un resumen de la liturgia de la palabra de los escrutinios cf. A. NOCENT, Iniciación cristiana, 1063.

76 "Las 'entregas' [...] tienden a la iluminación de los elegidos. En el Símbolo, en el que se recuerdan las grandezas y maravillas de Dios para la salvación de los hombres, se inundan de fe y de gozo los ojos de los elegidos; en la Oración dominical, en cambio, descubren más profundamente el nuevo espíritu de los hijos, gracias al cual, llaman Padre a Dios, sobre todo durante la reunión eucarística." (RICA 25. 2).

77 Cf. M. DUJARIER, Iniciación cristiana de los adultos, 173-175 para ver la propuesta de este autor sobre los ritos de preparación inmediata. 210-224.

78 Cf. A. SCHEER, ¿Es la vigilia pascual un rito de tránsito?, en Concilium 132 (1978) 
Como la iniciación cristiana lo es en el misterio de Cristo y de su Iglesia, la celebración del bautismo y la confirmación tiene lugar después de la bendición del agua.

"La renuncia a Satanás y la profesión de fe son un único rito, que en el Bautismo de los adultos adquiere pleno valor. Porque al ser el Bautismo el sacramento de la fe, con la que los catecúmenos se unen a Dios y al mismo tiempo el sacramento con el que renacen, muy acertadamente se antepone al Bautismo el gesto de cada uno de los elegidos [...] renuncian totalmente al pecado y a Satanás, y se abrazan al misterio de la Trinidad. Con esta profesión, hecha ante el celebrante y la comunidad, manifiestan la voluntad, madurada durante el tiempo del catecumenado, de entablar una alianza nueva con Cristo." (RICA 211).

Entre la renuncia y la profesión de fe se sitúa la unción con el óleo de los catecúmenos (salvo que se hubiese hecho como parte de los ritos de preparación inmediata). Este rito

"apunta a la necesidad de la fortaleza divina, para que el que va a ser bautizado, a pesar de las ataduras de la vida pasada, y superando la oposición del diablo, dé con decisión el paso de profesar la fe, y la mantenga sin desmayo a lo largo de toda su vida:" (RICA 212).

Esta secuencia ritual en la primera parte del sacramento muestra claramente los tres referentes de la iniciación: separación (renuncias), margen (unción de los catecúmenos) y agregación (profesión de fe). El bautismo -junto con los ritos explanativos (imposición de la vestidura blanca y la entrega del cirio encendido)-, la confirmación ${ }^{79}$ y la participación por primera vez en la eucaristía completan la iniciación sacramental y la agregación simbólica a la comunidad cristiana. El tiempo de la mistagogia deberá servir para hacer que los neófitos se inserten más plenamente en el misterio del que han participado ${ }^{80}$.

79 "Resumiendo la doctrina de los SS. Padres en sus catequesis mistagógicas, el sentido de los historiadores y de la gran mayoría de teólogos y liturgistas actuales, así como las directrices de la doctrina y de los rituales emanados del Concilio Vaticano II, creo que podríamos concluir diciendo que la Confirmación esencialmente confiere el don del Espíritu Santo, cuyo fin es la incorporación del neófito en la comunidad eclesial haciéndole experimentar más profundamente su filiación divina y confiriéndole el derecho y la obligación de participar plenamente en la celebración de los santos Misterios, en unión con sus hermanos." (A. FRANQUESA, El gran sacramento de la iniciación cristiana, en Phase (1990) 197).

80 Cf. M. DUJARIER, Iniciación cristiana de los adultos, 185-188. La catequesis mistagógica no es tanto una explicación cuanto una evocación compuesta de tres elementos: ac- 
Los 'lunes de pascua' son los días de evaluación del proceso de iniciación cristiana. Si al despertarse el neófito del 'sueño catecumenal', después de la vigilia en la que ha recibido los sacramentos de iniciación, se topa con una asamblea amorfa que no vive lo que dice creer, el desencanto por su parte estará asegurado ${ }^{81}$. El examen de los 'lunes de pascua' pondrá de manifiesto si realmente la Iglesia que ha iniciado a un candidato lo ha hecho realmente mediante su presencia y apoyo constante o si sólo fue un espejismo. El 'lunes de pascua' cualquiera podrá darse cuenta de si la iniciación del neófito ha cambiado y regenerado la vida de la comunidad cristiana o no. En el segundo caso, la iniciación no se habrá llevado a efecto porque jamás se realizó un proceso de iniciación cristiana al estar ausente una auténtica comunidad ${ }^{82}$.

El proceso de iniciación cristiana propuesto por el RICA nada tiene que ver con la 'magia'. Por el hecho de ejecutar los ritos que propone no se consigue automáticamente ninguna conversión. Las etapas litúrgicas del Ritual han de ir "al ritmo que marquen las etapas de fe. Tanto la catequesis como la liturgia deberán ser, pues, progresivas, y ambas deberán ir a la par. Pero lo que finalmente va a condicionar el avance de los candidatos, no serán ni los programas de catequesis, ni las ceremonias rituales, sino más bien la conversión de los catecúmenos y su progreso en la fe" 83 .

ciones y palabras de la liturgia, imágenes y temas bíblicos y analogías sacadas de la naturaleza y la cultura. El pensamiento mistagógico no es difícil, sólo es diferente; la mistagogia tiene más una lógica asociativo-poética que discursivo-filosófica cf. W. HARMLESS, Augustine and the Catechumenate, 364-367.

81 Cf. M. DUJARIER, Iniciación cristiana de los adultos, 33. La buena y mala liturgia no se crean a sí mismas, son el resultado de una salud y sensibilidad social e individual o de una enfermedad y patología también del mismo tipo cf. A. KAVANAGH, Initiation: Baptism and Confirmation, 262. "It is indeed an incongruity to welcome people into a 'community" of strangers." (R. A. KEIFER, Christian Initiation: the state of question, en Worship 48 (1974) 404). Sobre la dialéctica entre integración de los neófitos y la renovación de las comunidades cf. E. AlBERICH, Catecumenado moderno, 152.

82 "La iniciación a la vida cristiana y al compromiso evangelizador dependerá, en buena medida, del modo de ser y de vivir de cada comunidad como comunidad mistagoga. Y aquí tenemos otra de las carencias más significativas. Si una comunidad cristiana ha experimentado la transformación operada por la gracia será muy consciente de que sólo se puede admitir al sacramento a aquél que participa de esta misma experiencia. En consecuencia, la iniciación cristiana bien llevada renueva, en primer término, a las mismas comunidades eclesiales que la desarrollan." (J. SASTRE, Algunas claves para una pastoral renovada del sacramento de la confirmación, 57). Cf. F. GARITANO LASKURAIN, Hacia un proyecto de iniciación cristiana para una Iglesia local, en Teología y Catequesis 72 (1999) 104.

83 M. DUJARIER, Iniciación cristiana de los adultos, 28. 


\title{
III. 4.- Una reflexión... para no terminar
}

Hemos de reconocer que el proceso típico oficial propuesto en el primer capítulo del RICA no es el que más se ajusta a la demanda ritual que los 'nominalmente' católicos hacen a la Iglesia. Esto no implica que este modelo de la iniciación de adultos deje de ser la norma para la iniciación cristiana ${ }^{84}$. Lo normativo del proceso de iniciación cristiana gira en torno a la conversión a Jesucristo y la agregación a la Iglesia ${ }^{85}$. Somos conscientes de que estadísticamente, se suelen pedir ritos en momentos antropológicos densos de 'las cuatro estaciones de la vida': bautismo al comienzo de la misma, la primera comunión en la niñez, el matrimonio en la adultez y el funeral... jcuando Dios quiera!

\begin{abstract}
"Se percibe un cierto sincronismo fáctico entre las etapas decisivas de la vida, la tendencia del hombre a sacralizar estas etapas por medio de los llamados ritos de tránsito ('rites de passage') y la petición (por parte de los sujetos) y 'administración' (por parte de la Iglesia) de estos cuatro sacramentos de la religiosidad popular" 86 .
\end{abstract}

Hablamos de la 'demanda ritual' y no de la 'demanda sacramental' porque está lejos de demostrarse que lo que muchas personas solicitan tenga vinculación con lo que la Iglesia entiende por 'sacramento'. Parece haber un desfase entre la oferta sacramental de la Iglesia y demanda ritual del pueblo. El ser humano no puede dejar de ser un 'animal ritual' en el más noble y profundo sentido del término: el rito y el símbolo siempre son necesarios para expresar y acceder a lo más auténticamente humano de la vida. Puesto que

84 Cf. A. KAVANAGH, The norm of Baptism: the new Rite of Chistian Initiation of Adults, 146-147. Una norma no tiene nada que ver con las veces que se hace una cosa, sino con el patrón por el que las cosas deben hacerse. Las normas fijan las medidas del juicio que. nos ayudan a discernir lo que es normal, lo que es anormal aunque permisible y lo que es anormal e inadmisible cf. W. HARMLESS, Augustine and the Catechumenate, 13-14. La norma de la iniciación cristiana, por tanto, es que los sacramentos señalen el punto inicial en el que la fe personal se ha desarrollado suficientemente para ser abierta a la participación pública y la interacción social cf. A. KAVANAGH, ,Initiation: Baptism and Confirmation, 263-264.

$85 \mathrm{Cf}$. A. KaVANAGH, The norm of Baptism: the new Rite of Chistian Initiation of Adults, 151; M. del CAMPO GUILARTE, Iniciación cristiana, La, 1251.

86 D. BOROBIO, Los "cuatro sacramentos" de la religiosidad popular. Una crítica, en Concilium 132 (1978), 251. La ausencia de ritos de paso densos y significativos antropológicamente en la sociedad civil hace que algunos sacramentos ocupen esta función sin que su recepción signifique pertenencia alguna a la Iglesia cf. F. GARITANO LASKURAIN, Hacia un proyecto de iniciación cristiana para una Iglesia local, 101. 
todos los sacramentos son ritos pero no todos los ritos son sacramentos, el desfase entre oferta y demanda al que hemos hecho referencia hay que verlo como un signo del divorcio existente entre la fe eclesial y la fe personal de los que solicitan tales ritos ${ }^{87}$. Dionisio Borobio apunta cuatro rasgos que pueden servir, en principio, para indicar "el grado de con-cordancia o dis-cordancia existente entre lo que los sujetos piden; creen y expresan en los sacramentos y lo que los sacramentos significan, expresan y ofrecen al hombrex"88. Estos cuatro referencias serían: cristocéntrica, eclesial, sacramental y existencial ${ }^{89}$.

En contraste con este autor ${ }^{90}$. creemos que los sacramentos de iniciación cristiana no deben ser considerados como ritos de paso unidos a las transiciones bio-antropológicas. Son, por el contrario, ritos de paso cuyo sustrato no está en lo biológico-cultural sino en lo teológico-existencial: son ritos de paso de la no fe a la fe, de la fe religiosa a la fe cristiana, de la fe cristiana individual a la fe cristiana vivida eclesialmente ${ }^{91}$. De esta manera, los sacramentos del bautismo-confirmación-eucaristía han de ser considerados ritos de iniciación con la especificidad propia del misterio cristiano: la pascua de

87 "Los ritos sacramentales [...] son también un modo de integrar la vida en un proceso de socialización religiosa, un modo de significar cómo se quiere estar religiosamente en el mundo, una forma cualificada de decir que uno es católico o cristiano y no otra cosa. Poner en tela de juicio esta identidad supone muchas veces herir la conciencia en lo más íntimo. Para ellos ser cristiano es sobre todo querer serlo. No les preocupan ni las cuestiones dogmáticas, ni las exigencias morales, ni la contradicción entre 'su fe' y su vida. [...] Están bautizados: sencillamente por eso son cristianos. Y su derecho a recibir los sacramentos les parece indiscutible, sea cual sea la motivación que les impulsa." (D. BOROBIO, Los "cuatro sacramentos" de la religiosidad popular, 257). "Unless the Christian liturgy is an act of faith, it is not liturgy but ritual alone - compulsive at best or viciously psychotic at worst." (A. KAVANAGH,, Initiation: Baptism and Confirmation, 263). "Louis Marie Chauvert afirma [...] que la iniciación en el plano sacramental no se traduce en una iniciación en el plano existencial, y hablando de los sacramentos recibidos en la infancia resalta la desproporción entre la oferta y la demanda." (F. GARITANO LASKURAIN, Hacia un proyecto de iniciación cristiana para una Iglesia local, 97).

88 D. BOROBIO, Los "cuatro sacramentos" de la religiosidad popular, 261.

89 Cf. D. BOROBIO, Los "cuatro sacramentos". de la religiosidad popular, 261-263.

90 Cf. D. BOROBIO, Los “cuatro sacramentos” de la religiosidad popular, 258-259.

91 "Los sacramentos implican una cierta dimensión de ritos de tránsito, pero se relacionan con una fase de la conversión personal más que con un momento determinado de la existencia del individuo. Los sacramentos de iniciación sellan un proceso de conversión personal cuyo punto de partida, duración o momento culminante son propios y peculiares de cada individuo. [...] En consecuencia, si realmente tiene que haber unos ritos para los momentos clave del ciclo vital, éstos habrán de tener una forma y un significado distintos de los que corresponden a los sacramentos tradicionales. Habrán de ser ante todo ritos destinados a marcar aquellas ocasiones en que el problema de la transición personal, simbolizada en los sacramentos, se plantea en el contexto de los momentos de crisis pertenecientes al ciclo vital en sí." (D. POWER, La odisea del hombre en Cristo, 269). Cf. F. GARITANO LASKURAIN, Hacia un proyecto de iniciación cristiana para una Iglesia local, 102. 
Cristo celebrada y vivida dinámicamente en la comunidad cristiana como sacramento para el mundo. Las crisis vitales de tránsito (v.gr. el nacimiento), podrían ser ritualizadas, no por los sacramentos sino por otro tipo de celebraciones referidas a la llamada de Dios a entrar en comunión con Él por medio de la conversión y la fe en Jesucristo vivida en la comunidad creyente ${ }^{92}$. Pero esta posibilidad ha sido negada en un reciente documento de la Conferencia Episcopal Española aduciendo la posible confusión que podría crear (cf. IC 81). Quizá sea preferible mantener la perplejidad eclesial en la que estamos cuando alguien pide un rito y la Iglesia le $d a$ un sacramento sin el proceso iniciático que debería acompañarle ${ }^{93}$.

Tanto el proceso de iniciación cristiana llevado a cabo en los primeros siglos de la Iglesia como el propuesto por el capítulo primero del RICA no deben ser considerados como curiosidades arqueológicas o excepciones litúrgicas. Tampoco hay que intentar copiarlos para aplicarlos tal cual a nuestra situación concreta. Deben servirnos como iconos.

"What might this mean? Icons are images that one does not simply look at. Rather, they are images that one looks through, as one looks through a window. They help fix our gaze at mysteries that lie beyond any particular historical image: that is, the mystery that God is, the mystery that the Chrrch is, the mystery that we ourselves are. In this sense, [the catechumenate] as icon -in its very particularity, its very concreteness- can help fix our gaze 'beyond it to the living reality of which it is an embodiment.' But an icon is not simply a window. It is, in another sense, an image that helps us look back ourselves, as one might

92 Cf. D. POWER, La odisea del hombre en Cristo, 280-281; F. GARITANO LASKURAIN, Hacia un proyecto de iniciación cristiana para una Iglesia local, 101-103.

93 Ya en 1948, J. Colomb lamentaba la ausencia del catecumenado: "Ahora bien, el drama de nuestra época es que el mundo social se ha ido poco a poco descristianizando; el ambiente familiar, que depende del social [...] constituye muy raramente un ambiente cristiano formador de 'fieles'... Y no obstante continúan bautizándose casi todos los niños. Y así se bautizan los niños sin que se les ofrezca un catecumenado eficaz. Nuęstros niños cristianos, quizá en su mayoría no son iluminados; no son verdaderamente exorcizados. ¿Cómo podrán, sin un milagro de la gracia, permanecer fieles? De hecho, el catecismo, al menos en parte, debería asegurar el catecumenado necesario. No lo hace, y la razón principal es que no ha realizado los cambios de estructura que exige la desaparición de la Cristiandad [...]" (Citado por U. GIANETTO, Iniciación cristiana, en J. Gevaert (dir.), Diccionario de catequética, CCS, Madrid 1987, 465). Cf. A. M ${ }^{a}$ ALCEDO TERNERO, Anuncio misionero, en V. Ma Pedrosa et al., Nuevo diccionario de catequética I, San Pablo, Madrid 1990, 188-195. Joseph Moingt, por su parte, afirma: "El bautismo es el comienzo de un proceso que en realidad... no tendrá lugar. La eucaristía, que debería significar la entrada en la vida de la Iglesia, más bien resulta la salida en muchos casos. La institución bautismal fabrica más apóstatas prácticos que cristianos perseverantes" (Citato por F. GARITANO LASKURAIN, Hacia un proyecto de iniciación cristiana para una Iglesia local,91). 
look into a mirror. Its very otherness, its strangeness, casts a reflection back. In this sense, [the catechumenate] as icon might help us see ourselves more clearly. In its reflection, the contours and limits of our own teaching on the mysteries -that God is, that the Church is, that we ourselves are- might come into better focus" 94 .

Como afirma A. Kavanagh, el problema no es litúrgico, es social. Los problemas en la liturgia son síntomas de un problema más radical: el problema que somos nosotros mismos como comunidad de fe compartida. La recuperación de procesos de iniciación que respondan a la dinámica propia del crecimiento y maduración de la fe-conversión ha de llevar a replantear necesariamente "el mismo proyecto de Iglesia que se quiere promover y construir"95 debido a que la iniciación está en la raíz de lo que somos en cuanto comunidad cristiana. El problema de la Iglesia, podríamos decir, no está en el mundo sino en ella misma. "We have met the enemy, and he is us"96.

\section{CONCLUSIONES}

"Siempre que padecemos alguna estrechez o tribulación hemos de ver en ellas un aviso y, al mismo tiempo, una corrección. [...] ¿Qué sufre ahora, hermanos, el género humano de nuevo que no hayan sufrido nuestros padres? [...] Te encuentras con hombres que murmuran de los tiempos en que les ha tocado vivir, afirmando que fueron buenos los de nuestros padres. ¡Qué no murmurarían si pudieran volver al tiempo de sus padres! Piensas que los tiempos pasados fueron buenos porque no son los tuyos; por eso son buenos. [...] ¿Por qué, pues, piensas que los tiempos pasados fueron mejores que los tuyos? Desde aquel Adán hasta el Adán de hoy ha habido fatiga y sudor, espinas y abrojos ${ }^{97}$."

La condición humana tiene inscrita en su médula el carácter histórico del devenir. Los cambios de todo tipo-cósmicos, sociales y personales-

94 W. HARMLESS, Augustine and the Catechumenate, 347.

95 E. ALBERICH, Catecumenado moderno, 152.

96 A. KAVANAGH, Initiation: Baptism and Confirmation, 264. “[...] cuando percibimos que una determinada comunidad eclesial no acierta a iniciar en la fe a nuevos creyentes, o, como se acostumbra a decir coloquialmente, no sabe cómo hacer nuevos cristianos, estamos constatando en el fondo la incapacidad de esa comunidad para transmitir la fe, para vincular a nuevos creyentes al curso vivo de la Tradición." M. del CAMPO GUILARTE, Iniciación cristiana, La, 1257.

97 SAN Agustín, Serm. 346 C, 1. 
nos acompañan siempre, en todo lugar y de manera inevitable. La ambigüedad del cambio hace que nos situemos ante él de manera ambivalente: con temor respecto a lo no-conocido y con esperanza frente a lo porvenir. Ser persona es participar constantemente de este doble movimiento que se produce desde el nacimiento hasta nuestra sepultura. De todos modos, no todos los cambios tienen la misma dimensión: los más significativos nos marcan y modelan en nuestro ser más profundo. Los ritos de paso y los de iniciación están tan arraigados en las diferentes culturas porque simbolizan, expresan y ayudan a configurar los cambios importantes que todo ser humano experimenta.

En este estudio hemos intentado aproximarnos al tema de la iniciación cristiana desde la perspectiva de la antropología y la fenomenología religiosa, de la teología y de la praxis pastoral. Hemos querido desentrañar el significado profundo de lo iniciático para la identidad cristiana y para la misión de la Iglesia en los nuevos tiempos. La finalidad de este enfoque interdisciplinar es completar un mosaico en el que se pueda apreciar la variedad y riqueza de los elementos -no siempre evidentes- que lo conforman y, al mismo tiempo, percibir la complejidad de la iniciación cristiana como tarea de una Iglesia que no sólo se dice Madre, sino que tiene que serlo efectivamente dando a luz nuevos hijos, también en las circunstancias actuales.

Nuestra época, compleja como todas, nos deja perplejos: aceptarla tal como es nos parece insuficiente; demonizarla no aporta nada; añorar tiempos pasados no nos devuelve a ellos. Ciertamente, el tiempo que nos toca vivir nos duele a nosotros, no a nuestros antepasados. Las dificultades que tenemos que afrontar nos parecen excesivas porque no fuimos preparados para solucionarlas. Con todo, desde una lectura creyente de la realidad, hemos de seguir afirmando -quizá contra toda esperanza- que éste es el kairós de Dios para nuestra Iglesia, entre otras razones, porque no tenemos otro.

A continuación vamos a intentar proponer algunas de las conclusiones que se pudieran desprender de nuestro estudio aplicadas al ámbito de la iniciación cristiana.

1a. Nuestro ámbito socio-cultural tiene una cosmovisión fragmentada así como referencias plurales y divergentes de sentido radicalmente diferentes del mundo tradicional en el que se desarrollaban las iniciaciones clásicas. 
Al comienzo de nuestro trabajo, en el capítulo introductorio, constatamos la ruptura de los grandes metarrelatos, la pluralidad de pequeñas cosmovisiones, la falta de un suelo firme donde poner los cimientos de una nueva construcción social, la velocidad y profundidad de los cambios, la ausencia de referencias fiables que nos orienten hacia el futuro... La exaltación idolátrica de la adolescencia o 'complejo de Peter Pan', una 'generación sin padre' (H. Nouwen) ni maestros y el fenómeno de las 'identificaciones parciales' parecen ser síntomas de una sociedad enfermiza que no termina de encontrar orientaciones profundas que ofrecer a sus componentes. Con todo, la aspiración humana básica a tener una vida con sentido y a no resignarse con lo ya adquirido hablan en favor de un ser en constante búsqueda. Ésta, muchas veces errática, posibilita la apertura del hombre a una vida transmutada que la iniciación promete.

Lo que en una primera lectura puede presentarse como características negativas del postmoderno, admiten una lectura en clave positiva. Así, por ejemplo, el presentismo puede ser interpretado como el anhelo de un ser humano escaldado por las falsas promesas de las que ya está de vuelta. La autenticidad palpable es una exigencia que nuestros contemporáneos están dispuestos a apreciar.

Todo ello puede invitarnos al repliegue sobre las pequeñas certezas o, por el contrario, salir a campo abierto para descubrir nuevos horizontes. En esta travesía por el desierto nos encontramos y, debido a ello, despojarnos de pesados fardos -quizá útiles en otros tiempos-se nos impone como condición necesaria para no morir arroyados por las arenas del desierto que avanza inexorablemente y poder, paso a paso, alcanzar otras metas que jamás nos atrevimos a soñar.

$2^{a}$. Aunque tengan la misma estructura y secuencia ritual (preliminar, liminar y postliminar), los ritos de paso y los ritos de iniciación no se identifican. Los procesos de iniciación siempre hacen referencia al mundo de lo sagrado.

El peso de nuestro trabajo se ha centrado en el ámbito de la fenomenología religiosa. Con el capítulo segundo hemos intentado iluminar desde este ámbito los ritos de iniciación, tan arraigados y permanentes en las más variadas y distantes culturas. Ha sido el primer paso para descubrir que toda iniciación pretende insertar a un sujeto dentro de unos parámetros culturales y religiosos que configuran la identidad religiosa del 
grupo que inicia. El abigarrado mundo de la iniciación -con multitud de símbolos, ritos, clases y pruebas- muestra que es un fenómeno tan extendido como necesario para que una colectividad religiosa pueda ir agregando a nuevos miembros. Pertenecer a una comunidad no es un dato de la naturaleza sino de la cultura y, por ello, los datos naturales, aunque necesarios, nunca son suficientes para acceder a la nueva vida que la iniciación persigue. Una persona adquiere esa nueva vida por medio de complejos procesos iniciáticos que posibilitan, facilitan y permiten que un sujeto abandone su antigua condición para adquirir una nueva de la que la comunidad iniciante es encarnación. El proceso de iniciación, sea cual sea el tipo concreto de que se trate, tiene un objetivo religioso: la regeneración del sujeto mediante el acceso al mundo de lo sagrado que se vive en una comunidad concreta. Por esta razón, para que la iniciación sea tal, necesariamente ha de insertar al neófito en la vida de la comunidad que le ha iniciado.

$3^{\mathrm{a}}$. Los procesos de iniciación, para conseguir su objetivo, responden a la secuencia ritual de los ritos de paso estructurados en ritos y tiempos de separación, margen y agregación.

Todo proceso ritual de iniciación consta de fases o tiempos más o menos prolongados y de ritos. La iniciación, como una subclase de ritos de paso, tiene una fase preliminar (señalada con ritos de separación), otra liminar (con ritos de margen) y, por último, la fase postliminar (en la que se incluyen ritos de agregación).

El objetivo de la fase y ritos preliminares consiste en separar al candidato del marco de referencia familiar en el que había adquirido una identidad determinada. Si un proceso ritual de iniciación no quiere ser puramente formal debe posibilitar y exigir, de una $u$ otra manera, que el candidato lleve a cabo una verdadera y profunda ruptura con el 'mundo' en el que previamente desarrollaba su existencia. Los ritos de separación están encaminados a alcanzar este objetivo sin el cual la iniciación no podrá continuar.

La etapa liminar y los ritos de margen tienen como objetivo remodelar la personalidad del candidato para que adquiera una nueva identidad religiosa. Tiempo y esfuerzo son dos requisitos necesarios para que el tránsito de un tipo de existencia a otra se lleve a cabo. Enseñanzas, ritos, pruebas son algunos de los constitutivos para que la etapa liminar se cons- 
tituya como un tránsito religioso en el que todas las dimensiones de la persona (conocimiento, afectividad, relaciones, percepción del mundo, acceso a lo sagrado) se vean regeneradas. Como la iniciación siempre lo es en la vida de una comunidad concreta, los maestros de la iniciación han de transmitir a los novicios todo lo necesario para insertarse en ella de manera activa. Porque la comunidad encarna los valores a los que pretende iniciar, los maestros de la iniciación encarnan la autoridad de la tradición comunitaria sobre los candidatos que se constituyen como un grupo especial de iguales separado de la comunidad general. La separación liminar posibilita una experiencia única a los iniciandos debido a que han sido despojados su identidad previa ('ya no son lo que eran') pero aún no han accedido a la identidad que persiguen ('todavía no han llegado a ser lo que deben ser').

Toda iniciación contempla, después de la separación iniciática, una fase postliminar en la que el que el iniciado es agregado a la comunidad. En ella es acogido como miembro de pleno derecho porque es una persona nueva, ha sido regenerado. Los rituales de agregación suelen tener un carácter festivo por un doble motivo: en primer lugar, el candidato que se marchó marcado por la carencia ha muerto pero ha renacido como persona radicalmente nueva que puede integrarse en la vida religiosa comunitaria compartiendo sus mismos valores y destino; en segundo lugar, al agregar a un nuevo miembro, todo el grupo se regenera, renueva su propia iniciación al decirse lo que le constituye en sus aspectos más sagrados.

\section{El objetivo de la iniciación (la experiencia religiosa y la agrega-} ción a la comunidad que la encarna) se conseguirá tanto en cuanto la separación y el margen realicen en el candidato aquello que significan y persiguen.

La pura mecánica ritual no es suficiente para acceder al objetivo de la iniciación. Para ello, es necesario que la forma y el contenido del proceso iniciático se desarrollen de manera conjunta y armónica así como que el candidato participe existencialmente de ellos. En la medida que los factores que han modelado la antigua personalidad del candidato continúen vigentes, no podrá empezar la remodelación iniciática. Por ello, es necesario que sea arrancado existencialmente de ellos para ser expuesto a otros que le configurarán de manera nueva, durante la etapa de margen, 
como una persona religiosamente diferente e inserta en la comunidad que le está iniciando.

5a La dinámica de la iniciación cristiana responde, en sus aspectos fenomenológicos, a la secuencia de cualquier proceso de iniciación: pretende hacer romper al candidato con su modo de existencia previo, remodelar su identidad según el modelo de Cristo y agregarlo a la comunidad cristiana para que viva en ella y en medio del mundo su nueva condición.

Al comienzo del capítulo tercero, hemos querido perfilar los contornos de la identidad cristiana a la que la iniciación cristiana ha de introducir. Sin pretender ser exhaustivos, las clásicas virtudes teologales, la eclesialidad y la misión han sido propuestas como determinantes de dicha identidad. Entre identidad humana e identidad cristiana se da, al mismo tiempo, continuidad y discontinuidad. Si 'ser cristiano' no tuviera nada que ver con 'ser persona' el cristianismo sería totalmente alienante; si, por el contrario, se identificasen, el seguimiento de Cristo no aportaría novedad alguna. Esto mismo, en términos teológicos se puede formular afirmando que la redención en Cristo es plenificación de la creación o "nueva creación" (cf. Gal 6,15).

La llamada a la conversión es, en este sentido, la urgencia por romper con aquello que impide a la persona acoger la justificación gratuita de Dios para entrar en una nueva existencia. La conversión es también no sólo el origen de la identidad cristiana sino del inicio del proceso de iniciación que intentará hacerla madurar en todos sus dimensiones. La catequesis, partiendo de la conversión primera, profundizará la fe inicial para que se convierta en una fe madura. Los sacramentos de iniciación cristiana, por último, llevan a plenitud el cambio religioso del neófito agregándole a la comunidad eclesial para que viva su nueva condición en comunión con el resto del Cuerpo de Cristo y como sacramento para el mundo en todas las dimensiones de su vida.

$\mathrm{El}$ acercamiento al proceso de iniciación cristiana, tanto en el catecumenado antiguo como al modelo propuesto en el primer capítulo del RICA, nos ha permitido descubrir la cercanía estructural que dichos procesos mantienen con el resto de iniciaciones. La especificidad de la iniciación cristiana se nos revela en su dimensión cristocéntrica y eclesial. 
6a. El acontecimiento histórico que posiblemente ha marcado más profundamente la praxis de la iniciación cristiana ha sido el hecho de que el cristianismo pasara de ser una religión marginal y perseguida a la religión oficial del Imperio Romano.

La existencia de un proceso iniciático serio en la Iglesia durante los siglos II y III resulta ser una 'memoria peligrosa' para nuestra Iglesia actual. Pone en cuestión y critica profundamente lo que significa ser cristiano, el proceso para llegar a serlo y la misma praxis eclesial. De no haber existido ese breve espacio de tiempo, quizá el modelo normativo de iniciación cristiana sería el aplicado a los niños ${ }^{98}$. No hay acontecimiento pastoral en la historia de la Iglesia que cuestione tan seriamente nuestra praxis evangelizadora como la iniciación cristiana realizada en la cuenca del Mediterráneo durante los doscientos años previos al año 313.

La conversión era la condición subjetiva necesaria para que pudiera comenzar y llevarse adelante el proceso de iniciación cristiana. Correlativamente, el discernimiento de la autenticidad de esa conversión por parte de la Iglesia era la mediación objetiva necesaria para que el candidato pudiera ir accediendo a las etapas sucesivas de la iniciación cristiana. Discernimiento de la conversión, proceso catecumenal exigente y una comunidad de fe en la base eran las claves para que el proceso de iniciación cristiana cumpliera sus objetivos propios hasta el Edicto de Milán. Posterior y progresivamente, estos objetivos se fueron difuminando debido a un mayor peso social de la Iglesia, a una afluencia masiva de catecúmenos y a un relajamiento del tono evangélico de las comunidades cristianas.

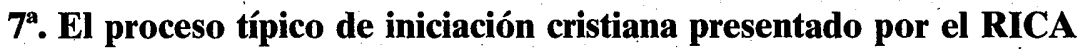
en su capítulo primero retoma la normatividad central de la secuencia iniciática: primera evangelización y conversión inicial (fase preliminar), catecumenado (fase liminar) y sacramentos de iniciación cristiana (fase postliminar).

El RICA es más importante en lo que presupone que en sus aspectos litúrgicos concretos. Dicho en otros términos, este Ritual presupone y so-

98 "La inexistencia de una 'edad de oro', a lo largo de la historia' de la Iglesia, en lo que se refiere a la iniciación cristiana de los niños, es una de las conclusiones a las que llegó, allá por el año 1951 y tras cumplida información y reflexión, el Centro de Pastoral Litúrgica de París." (M. RAMOS, Educación litúrgica e iniciación cristiana. La primera comunión de los niños, en Phase (1985) 117). 
licita el discernimiento de aquello que debe ocurrir en el interior de un candidato (fe y conversión) durante cada uno de los tiempos de la iniciación para que pueda ser admitido a la fase siguiente de la misma; presupone y demanda que la comunidad cristiana esté presente como trasfondo visible y meta de todo el proceso de iniciación; presupone y reclama en el candidato una fe y vida cristiana suficientemente madura no sólo antes de la recepción de los sacramentos sino también antes de franquear cada uno de los umbrales de los grados previos. Cuando estos presupuestos no son reales todo el proceso se resiente y devalúa.

El acercamiento a la fenomenología de la iniciación y a la iniciación cristiana en particular nos ha hecho vislumbrar interrogantes y campos abiertos. Las instituciones tradicionalmente iniciadoras (familia, escuela, Iglesia) quizás en el mejor de los casos siguen transmitiendo 'algo', a través de la instrucción y el aprendizaje, pero ya no inician. Por esta razón, se nos abren interrogantes principalmente desde tres ámbitos: el cultural, el eclesiológico y el catequético.

a) Dado que no estamos ubicados en una sociedad tradicional sino en una occidental postmoderna, quedan abiertos interrogantes profundos desde nuestro contexto cultural: ¿cómo podrán sobrevivir en este contexto, si es que lo hacen, las estructuras iniciáticas tradicionales? En un mundo donde los valores son tan cambiantes y etéreos ¿qué certezas básicas podrá transmitir la iniciación a las nuevas generaciones? En una cultura post-figurativa ¿dónde encontrar nuevos maestros que inicien en una tradición? ¿Acaso pervivirá alguna?

b) Desde el ámbito eclesiológico también se abren interrogantes: si el sujeto y ámbito de la iniciación cristiana es la Iglesia local ¿qué comunidades concretas serán capaces de iniciar y acoger a nuevos cristianos? Dado que la Iglesia no puede contentarse con aislarse del mundo al que está llamado a servir ¿cómo mantener la identidad cristiana en este medio social sin caer en fundamentalismos ni relativismos esterilizantes? Puesto que la iniciación cristiana es sobre todo obra de la gracia de Dios ¿qué rostro concreto ha de encarnar la Iglesia y qué organización habrá de adoptar para facilitarla? Ya que la iniciación cristiana intenta hacer madurar la nueva vida de fe suscitada por el Espíritu ¿cómo articular la iniciación para que no sea sólo integración pasiva de la persona en un grupo sino motor de conversión y regeneración también para la misma Iglesia? Puesto que uno de los fines de la iniciación es la inserción del candidato en el misterio de la Iglesia ¿a qué modelo de Iglesia iniciar? Y, puesto que la Iglesia que tenemos es el fruto de la iniciación que nos ha conformado 
como miembros suyos ¿cómo han de ser los procesos de iniciación para re-crear una Iglesia más evangélica?

c) El tercer ámbito desde el que surgen preguntas que deben ser contestadas es el de la catequética: si la catequesis es la acción evangelizadora que se sitúa después de la acción misionera ¿por qué no somos capaces de proponer criterios específicos para discernir la opción de fe de los candidatos? Si la acción catequética parte de la Iglesia y a ella tiende ¿por qué nos sentimos incapaces de actuar en consecuencia después de contemplar el desfase entre las estadísticas de la recepción de los sacramentos de iniciación y la pertenencia real a la Iglesia? Si el catecumenado de adultos es el modelo típico oficial que debe inspirar toda la catequesis ¿hasta cuando la mayor parte de las energías de la Iglesia se seguirán empleando en las catequesis de infancia y adolescencia siguiendo el modelo de 'cursos escolares'?

Con humildad hemos de reconocer que no tenemos respuestas para todos estos interrogantes. El esfuerzo de reflexión que se realiza desde los diferentes campos está ayudando a que la función iniciadora de la Iglesia se vaya planteando en la praxis con mayor rigor. Los resultados de nuestro trabajo han sido modestos; no han pretendido aportar soluciones a una problemática tan amplia sino plantear cuestiones previas a cualquier proyecto concreto de iniciación cristiana. Los pasos para su reestructuración han de ser necesariamente lentos pues suponen el cambio de mentalidad en toda la Iglesia y no sólo de reformas litúrgicas. Para seguir dando esos pasos será necesario pertrecharnos de 'una paciencia geológica' (P. R. Cren) con la intención de salvar una inercia que nos arrastra.

Como muchos dicen, 'no corren buenos tiempos para ser cristiano', pero ¿acaso los hubo en algún momento? Si hoy lo somos es, como decía el catecismo, 'por la gracia de Dios' y, deberíamos añadir, porque esa gracia se encarnó en una Iglesia, en unos hombres y mujeres que nos transmitieron la fe, nos enseñaron a vivirla y porque, también 'por la gracia de Dios', hemos seguido haciendo, día a día, una opción por ella en esta nuestra casta meretix. De una u otra manera, la iniciación cristiana siempre ha sido llevada a cabo en los dos mil años de historia que nos separan desde que Dios-Abba nos enviara al misionero de su amor incondicional y entrañable.

En un momento de la historia, los sacramentos de iniciación se separaron del proceso de iniciación cristiana catecumenal. La Iglesia consideró válido cambiar el orden, entendió que era mejor invertir la secuencia situando en primer lugar los sacramentos debido a la existencia de lo que 
algunos han llamado ‘catecumenado social'. En la actualidad la situación ha vuelto a cambiar. ¿Tiene la Iglesia capacidad para volver a replantear su dinámica iniciática ante la mutación de las circunstancias socio-culturales? Creemos que sí: El lastre milenario de una praxis pastoral de cristiandad supone un freno que no podrá ser levantado por francotiradores aislados sino por un proyecto globalmente planteado y asumido que ha de contemplar de raíz todas las acciones eclesiales. Otra cuestión es si la Iglesia estará preparada y tendrá el valor suficiente para hacer el replanteamiento reclamado por las nuevas circunstancias.

\section{BIBLIOGRAFÍA}

Agustín, San, Confesiones, trad. J. Cosgaya, BAC, Madrid 1986.

Agustín, San, La catequesis de los principiantes, en Obras completas XXXIX, trad. J. Oroz Reta, BAC, Madrid 1988, 448-534.

Agustín, San, La fe y las obras, en Obras completas XXXIX, trad. T. C. Madrid, BAC, Madrid 1988, 546-615.

Agustín, San, Comentario sobre el salmo 119, en Obras completas XXII, trad. B. Martín Pérez, BAC, Madrid 1967; 204-222.

Agustín, San, Sermón 56, en Obras completas X, trad. L. Cilleruelo et al., BAC, Madrid 1983, 111-130.

AGustín, San, Sermón 57, en Obras completas X, trad. L. Cilleruelo et al., BAC, Madrid 1983, 131-144.

Agustín, San, Sermón 58, en Obras completas X, trad. L. Cilleruelo et al., BAC, Madrid 1983, 144-157.

Agustín, San, Sermón 59, en Obras completas X, trad. L. Cilleruelo et al., BAC, Madrid 1983, 157-162.

Agustín, San, Sermón 212, en Obras completas XXIV, trad. P. de Luis, BAC, Madrid 1983, 145-149.

Agustín, San, Sermón 213, en Obras completas XXIV, trad. P. de Luis, BAC, Madrid 1983, 150-162.

Agustín, San, Sermón 214, en Obras completas XXIV, trad. P. de Luis, BAC, Madrid 1983, 163-176.

Agustín, San, Sermón 215, en Obras completas XXIV, trad. P. de Luis, BAC, Madrid 1983, 177-186.

Agustín, San, Sermón 216, en Obras completas XXIV, trad. P. de Luis, BAC, Madrid 1983, 186-198.

Agustín, San, Sermón 227; en Obras completas XXIV, trad. P. de Luis, BAC, Madrid 1983, 285-288.

Agustín, San, Sermón 228, en Obras completas. XXIV, trad. P. de Luis, BAC, Madrid 1983, 289-292. 
Agustín, San, Sermón 229, en Obras completas XXIV, trad. P. de Luis, BAC, Madrid 1983, 297-301.

Agustín, San, Sermón 260 A, en Obras completas XXIV, trad. P. de Luis, BAC, Madrid 1983, 617-622.

AGustín; San, Sermón 272, en Obras completas XXIV, trad. P. de Luis, BAC, Madrid 1983, 766-769.

Agustín, San, Sermón 346 C, en Obras completas XXVI, trad. P. de Luis, BAC, Madrid 1983, 130-134.

Agustín, San, Tratado XI sobre el Evangelio de San Juan, en Obras completas XIII, trad. T. Prieto, BAC, Madrid 1955, 311-335.

Alberich, Emilio, Catecumenado moderno, en J. Gevaert (dir.), Diccionario de catequética, CCS, Madrid 1987, 149-153.

Alberoni, Francesco, El árbol de la vida. Acerca de las fuerzas, los deseos y las pasiones que nos permiten vivir, Gedisa, Barcelona $1991^{3}$.

Alcedo, Antonio, Hacia un vocabulario común sobre la iniciación cristiana, en Teología y Catequesis 28 (1988) 643-647.

Alcedo Ternero, Antonio $\mathrm{M}^{\mathrm{a}}$, Anuncio misionero, en V. $\mathrm{M}^{\mathrm{a}}$ Pedrosa et al., Nuevo diccionario de catequética I, San Pablo, Madrid 1990, 188-195.

Ambrosio, San, Explicación del Símbolo, en Ambrosio, San, La iniciación cristiana. (La explicación del Símbolo, los Sacramentos, los Misterios), C. Basevi (ed.), Rialp, Madrid 1977, 23-39.

Ambrosio, San, Los Misterios cristianos, en Ambrosio, San, La iniciación cristiana. (La explicación del Símbolo, los Sacramentos, los Misterios), C. Basevi (ed.), Rialp, Madrid 1977, 121-151.

Ambrosio, San, Los Sacramentos, en Ambrosio, San, La iniciación cristiana. (La explicación del Símbolo, los Sacramentos, los Misterios), C. Basevi (ed.), Rialp, Madrid 1977, 43-117.

Ambrosio, San, Tratado sobre el Evangelio de San Lucas en Obras de San Ambrosio I, M. Garrido Bonaño (ed.), BAC, Madrid 1966.

Ambrosio, San, La iniciación cristiana. (La explicación del Símbolo, los Sacramentos, los Misterios), C. Basevi (ed.), Rialp, Madrid 1977.

AUGÉ, Marc, Los "no lugares". Espacios del anonimato. Una antropología de la sobremodernidad, Gedisa, Barcelona $1998^{4}$.

Basurko, Xabier, Hacia una pastoral del bautismo, en Teología y Catequesis 18 (1986) 249-260.BASURKO, Xabier, La eucaristía en la iniciación cristiana, en Teología y Catequesis (1991) 57-70.

Berger, Peter L. - LuCKMANn, Thomas, Modernidad, pluralismo y crisis de sentido.

La orientación del hombre moderno, Paidós, Barcelona 1997.

BONNEFOY, Yves (dir.), Diccionario de las mitologías y de las religiones de las sociedades tradicionales y del mundo antiguo II, Destino, Barcelona 1996.

BONNEFOY, Yves (dir.), Diccionario de las mitologías y de las religiones de las sociedades tradicionales y del mundo antiguo IV, Destino, Barcelona 1998. 
Borobio, Dionisio, Los “cuatro sacramentos" de la religiosidad popular. Una critica, en Concilium 132 (1978) 249-266.

Borobio, Dionisio, Catecumenado, en C. Floristan - J. J. Tamayo (eds.), Conceptos fundamentales del cristianismo, Trotta, Madrid 1993, 131-150.

Bravo, Antonio, Adultos y fe adulta, en Teología y Catequesis 2 (1982) 177-191.

BÜHLER, Pierre, La identidad cristiana. Entre la objetividad y la subjetividad, en Concilium 216 (1988) 181-194.

CAmpo GuIlarte, Manuel del, Iniciación cristiana, La, en V. Ma Pedrosa et al., Nuevo diccionario de catequética I, San Pablo, Madrid 1990, 1238-1260.

CaÑIZAREs Llovera, Antonio, Los sacramentos de iniciación cristiana, en Teología y Catequesis 28 (1988) 629-642.

CASTANEDA, Carlos, Viaje a Ixtlán. Las lecciones de don Juan, Fondo de Cultura Económica, Madrid $1988^{12}$.

Cervantes, Miguel de , El ingenioso hidalgo don Quijote de la Mancha, J. J. Allen (ed.), Cátedra, Madrid 198810, 2 vols.

Crrilo de Jerusalén, San, Catequesis: Procatequesis, C. Elorriaga (ed.), Desclée de Brouwer, Bilbao 1991, 36-52.

Cirilo de Jerusalén, San, Catequesis: Mistagógica I, C. Elorriaga (ed.), Desclée de Brouwer, Bilbao 1991, 496-503.

Cirilo de Jerusalén, San, Catequesis: Mistagógica II, C. Elorriaga (ed.), Desclée de Brouwer, Bilbao 1991, 504-510.

Cren, Pierre-R., Une patience géologique, en Lumière et Vie 137 (1978) 81-95.

DANIElou, Jean - Du ChARLAT, Regine, La catequesis en los primeros siglos, Studium, Madrid 1975.

Della TORRE, Luiggi, Iniciación cristiana de los adultos (Ritual de la), en J. Gevaert (dir.), Diccionario de catequética, CCS, Madrid 1987, 467-469.

Díaz, Carlos, Símbolos vocacionales y equi-vocacionales en los nuevos jóvenes de la vieja Europa, en Todos Uno 97 (1989) 39-56.

DíAZ, Carlos, Ni Marx ni Kierkegaard: el otoño teológico postmoderno, en Revista Católica Internacional Communio 12 (1990) 159-170.

Didaché, en Didaché. Doctrina Apostolorum. Epístola del Pseudo-Bernabé, J. J. Ayán Calvo (ed.), Ciudad Nueva, Madrid 1992, 80-111.

Diez DE Velasco, Francisco, Hombres, ritos, Dioses. Introducción a la.Historia de las Religiones, Trotta, Madrid 1995.

Discurso a Diogneto, en Padres Apostólicos, trad. D. Ruiz Bueno, BAC, Madrid 1950, 845-860.

DRAVET, Jean, El noviciado, iniciación a la vida religiosa, en Vida Religiosa 75 (1993) 388-393.

DUJARIER, Michel, Breve historia del catecumenado, Descleé de Brouwer, Bilbao 1986.

DUJARIER, Michel, Iniciación cristiana de los adultos. Comentario histórico y pastoral del nuevo Ritual, Desclée de Brouwer, Bilbao 1986. 
ECHEVERRÍA, Javier, Los señores del aire: Telépolis y el Tercer Entorno, Destino, Madrid 1999.

EgERIA, Itinerario, A. Arce (ed.), BAC, Madrid 1980.

Eliade, Mircea, La búsqueda, Megápolis, Buenos Aires 1971.

ElIADE, Mircea., La prueba del laberinto (conversaciones con Claude-Henri Rocquet), Cristiandad, Madrid 1980

Eliade, Mircea, Lo sagrado y lo profano, Labor, Barcelona $1985^{6}$.

ElIADE, Mircea, Tratado de historia de las religiones. Morfología y dialéctica de lo sagrado, Círculo de Lectores, Barcelona 1990.

Eliade, Mircea, El mito del eterno retorno. Arquetipos y repetición, Alianza, Madrid 19927.

Eliade, Mircea, Herreros y alquimistas, Alianza, Madrid $1993^{4}$.

ELIADE, Mircea, Mito y realidad, Labor, Barcelona 19942.

ELIADE, Mircea, El vuelo mágico, Siruela, Madrid 1995.

ElIADE, Mircea, Initiation: An Overview, en M. Eliade (ed.), The Encyclopedia of Religion VII, Simon \& Chuster Macmillan, New York 1995, 225-229.

ElIADE, Mircea, Iniciaciones místicas, Taurus, Madrid 1998.

ELORRIAGA, Carlos, Bautismo y catecumenado en la tradición patrística y litúrgica (Una selección de textos), Grafite, Baracaldo 1998.

Epístola del Pseudo-Bernabé, en Didaché. Doctrina Apostolorum. Epistola del Pseudo-Bernabé, J. J. Ayán Calvo (ed.), Ciudad Nueva, Madrid 1992, 150231.

Equipo de CATEquetas de Euskal-Herria, Fe y conversión en V. M $^{a}$ Pedrosa et al., Nuevo diccionario de catequética I, San Pablo, Madrid 1990, 960-971.

Evdokimov, Paul, El arte del icono. Teología de la belleza, Publicaciones Claretianas, Madrid 1991.

FABRY, Joseph B., La búsqueda de significado. La logoterapia aplicada a la vida, Fondo de Cultura Económica, México 1977.

FERNÁNDEZ DEL RIESGO, Manuel, La posmodernidad y la crisis de los valores religiosos, en G. Vattimo et. al., En torno a la posmodernidad, Anthropos, Barcelona 1990,77-101.

FINKIELKRAUT, Alain, La derrota del pensamiento, Anagrama, Barcelona 19872.

Floristán, Casiano, Pertenencia a la Iglesia y Catecumenado, en Phase (1971) 349-360.

Floristán, Casiano, Para comprender el catecumenado, Verbo Divino, Estella 1989.

FRANQUESA, Adalbert, El gran sacramento de la iniciación cristiana, en Phase (1990) 185-209.

Fromm, Erich, Psicoanálisis de la sociedad contemporánea. Hacia una sociedad sana, Fondo de Cultura Económica, México 19719.

Fromm, Erich, ¿Tener o ser?, Fondo de Cultura Económica, Mexico 19817.

Gamarra MAYor, Saturnino, Identidad cristiana, en V. $\mathrm{M}^{\mathrm{a}}$ Pedrosa et al., Nuevo diccionario de catequética I, San Pablo, Madrid 1990, 1166-1177. 
Garitano Laskurain, Félix, Hacia un proyecto de iniciación cristiana para una Iglesia local, en Teología y Catequesis 72 (1999) 89-118.

GARrido, Alfonso, La Iglesia en el pensamiento de Paul Tillich, Sígueme, Salamanca 1979.

GARRIDO, Alfonso, Profanidad y trascendencia en el "Primer Mundo", en Biblia y Fe 15 (1989) 405-420.

GELABERT, Martín, Aspectos teológicos de la iniciación cristiana, en Teología y Catequesis 72 (1999) 43-62.

Gianetro, Ubaldo, Iniciación cristiana, en J. Gevaert (dir.), Diccionario de catequética, CCS, Madrid 1987, 464-466.

GINEL VIELVA, Álvaro, La iniciación cristiana como lugar especial de la formación del lenguaje religioso, en Teología y Catequesis 4 (1982) 509-525.

GómEZ, Amalia El envejecimiento como reto politico y social del siglo XX en $A B C$ (5-10-1999) 40.

GONDAL, Marie-Louise, Iniciación cristiana, Mensajero, Bilbao 1990.

GonzÁlez, Ramiro, La mistagogía en el Ritual de la Iniciación Cristiana de Adultos, en Phase (1992) 381-393.

Groppo, Giuseppe, Catecumenado antiguo, en J. Gevaert (dir.), Diccionario de catequética, CCS, Madrid 1987, 146-149.

HaArbeck, Hermann, Prueba, en L. Coenen et al., Diccionario teológico del Nuevo Testamento III, Sígueme, Salamanca 1983, 434-436.

HALDER, Alois - Welsch, Wolfgang, Arte y religión, en A. Álvarez Bolado et al. (dir.), Fe cristiana y Sociedad moderna, SM, Madrid 1984, 50-78.

Harmless, William, Augustine and the Catechumenate, The Liturgical Press, Collegeville 1995.

HARRIS, Marvin, Introducción a la antropología general, Alianza, Madrid 1981.

HerráeZ, Fidel, Conversión, en C. Floristán - J. J. Tamayo (eds.) Conceptos fundamentales del cristianismo, Trotta, Madrid 1993, 239-256.

HiPólito DE ROMA, San, La Tradición Apostólica, Lumen, Buenos Aires 1981.

Hoeber, E. Adamson - WeAver, Thomas, Antropología y experiencia humana, Omega, Barcelona $1985^{5}$.

Holmes, Urban T., Liminality and liturgy, en Worship 47 (1973) 386-397.

JUNG, Carl G., Respuesta a Job, Fondo de Cultura Económica, México 1973.

KANT, Immanuel, Respuesta a la pregunta: ¿Qué es la Ilustración?, en J. B. Erhard et al., ¿Qué es Ilustración?, Tecnos, Madrid 19892, 17-29.

KAVAFIS, Konstantinos, Ítaca, en 56 poemas, Mondadori, Madrid 1998, $23-24$.

KaVANAGH, Aidan, Initiation: Baptism and Confirmation, en Worship 46 (1972) 262-276.

KaVANAGH, Aidan, Christian initiation of adults: the rites, en Worship 48 (1974) 318-335.

KaVAnagh, Aidan, The norm of Baptism: the new Rite of Chistian Initiation of Adults, en Worship 48 (1974) 143-152. 
KAVANAGH, Aidan, Los acontecimientos del ciclo vital. Los ritos civiles y el cristianismo, en Concilium 132 (1978) 167-181.

KeIFER, Ralph A., Christian Initiation: the state of question, en Worship 48 (1974) 392-404.

Kimball, Solon T., Gennep, Arnold van, en Enciclopedia Internacional de las ciencias sociales V, Aguilar, Madrid 1975, 109-110.

KING, Alexander - SCHNEIDER, Bertrand, Informe al Club de Roma. La primera revolución mundial, Plaza \& Janés, Barcelona 1991.

LABOA, Juan María, La larga marcha de la Iglesia, Sociedad de Educación Atenas, Madrid 1985.

LAMET, Pedro Miguel, La fiebre del oro y el hombre "light", en Sal Terrae 78 (1990) 425-433.

LIPOVETSKY, Giles, La era del vacío. Ensayos sobre el individualismo contemporáneo, Anagrama, Barcelona $1988^{3}$.

LÓPEZ, Julián, La iniciación cristiana, inserción en Jesucristo y en la vida de la Iglesia, en Phase 218 (1997) 117-132.

LóPEZ CALvo, Andrés, La iniciación cristiana: una problemática actual, en Teología y Catequesis 72 (1999) 7-16.

LóPEZ SÁEZ, Jesús, Catecumenado e inspiración catecumenal, en V. M ${ }^{\mathrm{a}}$ Pedrosa et al., Nuevo diccionario de catequética I, San Pablo, Madrid 1990, 281-295.

LYOTARD, Jean-François, La condición postmoderna. Informe sobre el saber, Cátedra, Madrid $1986^{2}$.

MAIR, Lucy, Introducción a la antropología social, Alianza, Madrid $1986^{8}$.

MARDONES, José $\mathrm{M}^{\mathrm{a}}$, Postmodernidad y Cristianismo. El desafío del fragmento, Sal Terrae, Santander 1988.

MARTín VELASCO, Juan, Lo ritual en las religiones, SM, Madrid 1986.

MARTÍN VELASCO, Juan, Introducción a la fenomenología de la religión, Cristiandad, Madrid 19874.

MARTín Velasco, Juan, El reto de los alejados: ¿Un cambio de rumbo para la evangelización?, en Sal Terrae 78 (1990) 39-52.

MARTín Velasco, Juan, El malestar religioso de nuestra cultura, Paulinas, Madrid 1993.

MARTÍNEZ, Francisco Javier, Iniciación y catequesis en la Iglesia antigua: apuntes marginales, en Teología y Catequesis 4 (1984) 535-550.

MARTÍnez CoRTÉs, Javier, Me divierto luego existo, en Sal Terrae 77 (1989) 793802.

Martínez Holgado, Javier, En el centro de la Burbuja. (En torno al narcisismo), en Sal Terrae 77 (1989) 803-816.

Matos Holgado, Manuel, La catequesis como Traditio evangelii in symbolo, en Actualidad Catequética 106 (1982) 95-107.

Matos Holgado, Manuel, Intento de descripción de los itinerarios iniciáticos más comunes en la actual práctica eclesial española, en Teología y Catequesis 28 (1988) 621-627 
MAZA BAZÁn, Pedro, Para entender la postmodernidad, en Estudio Agustiniano 26 (1989) 391-404.

MEAD, Margaret, Cultura y compromiso. El mensaje de la nueva generación, Gedisa, Barcelona 19973 .

MEDINA, Miguel Ángel, La iniciación como proceso de madurez socio-religiosa. Breve recorrido por la historia, en Teología y Catequesis 72 (1999) 17-41.

METz, Johannes B., La incredulidad como problema teológico, en Concilium 6 (1965) 63-83.

METZ, Johannes B., ¿Necesita la Iglesia una nueva reforma? (Una respuesta católica), en Concilium 54 (1970) 79-90.

METz, Johannes B., En lugar de un editorial, en Concilium 66 (1971) 319-325.

METZ, Johannes B., El futuro a la luz del memorial de la pasión. Una forma actual de la responsabilidad del creyente, en Concilium 76 (1972) 317-334.

METz, Johannes B., La fe, en la historia y la sociedad. Esbozo de una teología política fundamental para nuestro tiempo, Cristiandad, Madrid 1979.

METZ, Johannes B., ¿Religión mesiánica o burguesa? Sobre la crisis de la Iglesia en la República Federal Alemana, en Concilium 145 (1979) 247-262.

METZ, Johannes B., Más allá de la religión burguesa. Sobre el futuro del cristianismo, Sígueme, Salamanca 1982.

METZ; Johannes B., La trampa electrónica. Notas teológicas sobre el culto religioso en la televisión, en Concilium 250 (1993) 1035-1040.

MiER VÉlEZ, Antonio de, Supersticiones y horóscopos entre los cristianos visigodos y francos, en Religión y Cultura 195 (1995) 811-839.

Mrguel, Amando de, La noche y los jóvenes, en ABC (27-8-1996) 3.

Mrtchell, Nathan, Christian Initiation: Decline and Dismemberment, en Worship 48 (1974) 458-479.

Movilla, Secundino, Del catecumenado a la comunidad. Clarificaciones teológico-pastorales, Paulinas, Madrid 1982.

Myerhoff, Barbara G. - CAmino, Linda A. - Turner, Edith, Rites of passage: An overview, en M. Eliade (ed.), The Encyclopedia of Religion XI, Simon \& Chuster Macmillan, New York 1995, 380-386.

NATAL, Domingo, Hacia un cristianismo postmoderno, en Estudio Agustiniano 25 (1990) 13-32.

Nocent, Adrien, Iniciación cristiana, en D. Sartore - A. M. Triacca (dir.), Nuevo diccionario de liturgia, Paulinas, Madrid 1987, 1051-1070.

OÑATE Zubia, Teresa, Lyotard: La escritura de la disensión, en Revista de Occidente 73 (1987), 109-127.

Oroz ReTA, José, Introducción a "De catechizandis rudibus", en Agustín, San, Obras completas XXXIX, BAC, Madrid 1988, 425-446.

PABLo, Valentín de, Juventud actual y pastoral. Retos y posibilidades para la Pastoral juvenil, en Lumen 39 (1990) 294-314.

PANIKKAR, Raimon, La experiencia de Dios, PPC, Madrid 1994. 
PASQUIER, Abel, Sociedad de iniciación, sociedad en busca de iniciaciones, en Concilium 142 (1979) 171-187.

Pedrosa, Vicente $\mathrm{M}^{\mathrm{a}}$, Causas de la escasez de grupos de catequesis de adultos, en Sínite 106 (1994) 315-341.

PIKAZA, Xabier, Carácter sacramental del mundo. Reflexión filosófico-teológica en Biblia y Fe 15 (1989) 332-369.

POWER, David, La odisea del hombre en Cristo, en Concilium 132 (1978) 267-282.

QUINZÁ, Xavier, Los signos de un tiempo perplejo. Cómo evangelizar el nihilismo positivo de nuestra sociedad, en Sal Terrae 78 (1990) 755-763.

RAHNER, Karl, Conversión, en Sacramentum Mundi I, Herder, Barcelona 1972, 976-985.

RAMOS, Manuel, Educación litúrgica e iniciación cristiana. La primera comunión de los niños, en Phase (1985) 117-139.

REEDY, William J. (ed.), Becoming a Catholic Christian. A symposium on Christian Initiation, William H. Sadlier, New York $1981^{3}$.

RESINES, Luis, El catecumenado en "De catechizandis rudibus", en Estudio Agustiniano 22 (1987) 373-393.

RICHTER, Klemens, El rito de iniciación juvenil: ¿una confirmación secularizada?, en Teología y Catequesis 21 (1987) 87-111.

RIES, Julien (ed.), Ritos de iniciación, EGA, Bilbao 1994.

RILEY, Hugh M., Christian Initiation. A Comparative Study of the Interpretation of the Baptismal Liturgy in the Mystagogical Writings of Cyril of Jerusalem, John Chrysostom, Theodore of Mopsuestia and Ambrose of Milan, The Catholic University of America Press, Washington D.C. 1974.

RocheblaVE-SPENLÉ, Anne-Marie, El poder desenmascarado, Sociedad de Educación Atenas, Madrid 1975.

RoF CARBALlo, J. Urdimbre afectiva y enfermedad. Introducción a una medicina dialógica, Labor, Barcelona 1961.

Romero Pose, Eugenio, Catequesis en la época patrística, en V. Ma Pedrosa et al., Nuevo diccionario de catequética I, San Pablo, Madrid 1990, 362-374.

Rovira Belloso, Josep María, Fe y cultura en nuestro tiempo, Sal Terrae, Santander 1988

SASTRE, Jesús, Algunas claves para una pastoral renovada del sacramento de la confirmación, en Teología y Catequesis 74 (2000) 45-74.

SCHARFENBERG, Joachim, Madurez humana y símbolos cristianos, en Concilium 132 (1978) .182-195.

SCHEER, Anthonius, ¿Es la vigilia pascual un rito de tránsito? Estudio sobre la naturaleza de la celebración litúrgica de la Pascua, en Concilium 132 (1978) 210-224.

SCHNEIDER, Bertrand, Razones para vivir y esperar en la nueva sociedad mundial, en El País (25-11-1988) 40.

SECKLER, Max et al., Lenguaje literario y lenguaje religioso, en A. Álvarez Bolado et al. (dir.), Fe cristiana y Sociedad moderna, SM, Madrid 1984, 80-142. 
SMITs, Kenneth F., Confirmation Re-examined: An Evolving Theology and Practice, en Worship 48 (1974) 21-29.

TAMaYo, Juan-José, Mínimos fundamentales para ser cristianos hoy, en Misión Joven 268 (1999) 13-22.

TOFFLER, Alvin, El "shock" del futuro, Plaza \& Janés, Barcelona 1990.

TONELLI, Ricardo, Retrato de un joven cristiano, en Misión Joven 268 (1999) 23-32.

TURner, Victor, Passages, Margins, and Poverty: Religious Symbols of Communitas, en Worship 46 (1972) 390-412.

Turner, Victor, Passages, Margins, and Poverty: Religious Symbols of Communitas (part II), en Worship 46 (1972) 482-494.

TURNER, Victor, El proceso ritual. Estructura y antiestructura, Taurus, Madrid 1988.

TURNER, Victor, La selva de los símbolos. Aspectos del ritual ndembu, Siglo XXI, Madrid $1990^{2}$.

Turner, Victor, Rites of passage: A Few Definitions, en M. Eliade (ed.), The Encyclopedia of Religion XI, Simon \& Chuster Macmillan, New York 1995, 386-387.

Unamuno, Miguel de, Mi religión y otros ensayos breves: Escepticismo fanático, Espasa Calpe, Madrid 19685, 140-145.

UnAmuno, Miguel de, Mi religión y otros ensayos breves: Tres generaciones, Espasa Calpe, Madrid 19685, 79-85.

VAladier, Paul, La Iglesia en proceso. Catolicismo y sociedad moderna, Sal Terrae, Santander 1990.

VAN GENNEP, Arnold, Los ritos de paso. Estudio sistemático de las ceremonias de la puerta y del umbral, de la hospitalidad, de la adopción, del embarazo y del parto, del nacimiento, de la infancia, de la pubertad, de la iniciación, de la ordenación, de la coronación, del noviazgo y del matrimonio, de los funerales, de las estaciones, etc., Taurus, Madrid 1986.

VATtimo, Gianni, Las aventuras de la diferencia. Pensar después de Nietzsche y Heidegger, Península, Barcelona $1990^{2}$.

VAttimo, Gianni, Creer que se cree, Paidós, Barcelona 1996.

VEGA, José, A propósito de las "Edades del hombre", en Religión y Cultura 35 (1989) 183-204.

VERDÚ, Vicente, El planeta americano, Anagrama, Barcelona 19965.

Vergote, Antonie, Psicología religiosa, Taurus, Madrid 1969.

VernetTe, Jean - BourgeoIs, Henri, Perspectivas catecumenales. Un futuro para la fe, Marova, Madrid 1980.

MANUEl BerJón MARTíNEZ, OSA

Iquitos (Perú) 